\title{
Carbocyclic Nucleosides
}

\section{Victor E. Marquez and Mu-Ill Lim}

Medicinal Chenistry Section, Laboratory of Pharmacology and Experimental Therapeutics, Developmental Therapeutics Program, Division of Cancer Treatment, National Cancer Institute, National Institutes of Health, Bethesda, Maryland 20205

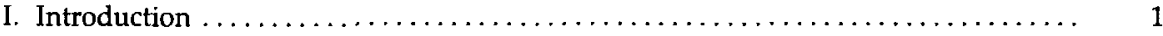

II. The Chemistry of Carbocyclic Nucleosides $\ldots \ldots \ldots \ldots \ldots \ldots \ldots \ldots \ldots \ldots \ldots \ldots, 2$

A. General Discussion . .................................... 2

B. Synthesis of Carbocyclic Ribofuranosylamine $\left(\mathrm{C}-\mathrm{rib}-\mathrm{NH}_{2}\right) \ldots \ldots \ldots \ldots \ldots \ldots \ldots$

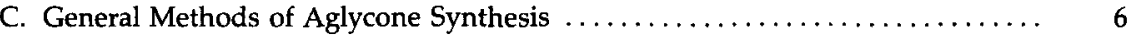

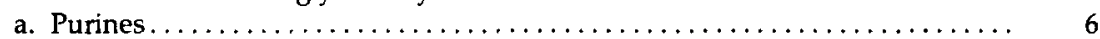

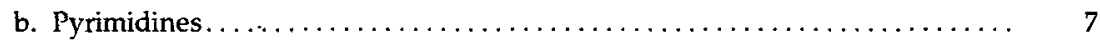

III. Purine Carbocyclic Nucleosides $\ldots \ldots \ldots \ldots \ldots \ldots \ldots \ldots \ldots \ldots \ldots \ldots \ldots \ldots \ldots \ldots \ldots \ldots$

A. Purine Carbocyclic Nucleosides. . . . . . . . . . . . . . . . . . . . 7

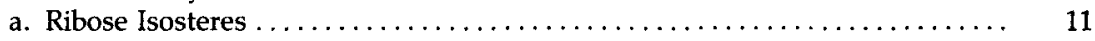

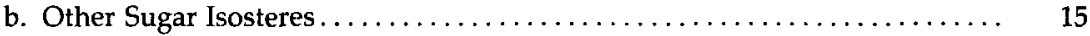

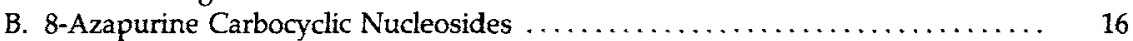

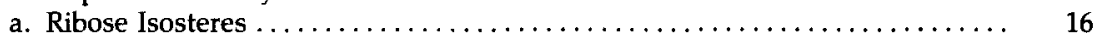

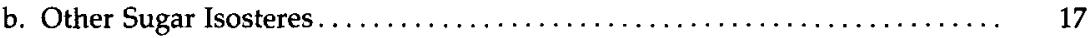

C. 3-Deazapurine Carbocyclic Nucleosides $\ldots \ldots \ldots \ldots \ldots \ldots \ldots \ldots \ldots \ldots \ldots \ldots \ldots \ldots \ldots \ldots$

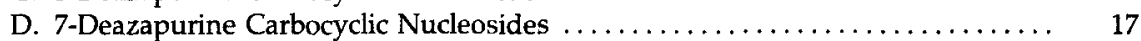

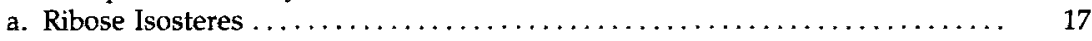

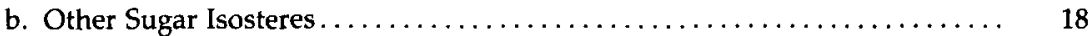

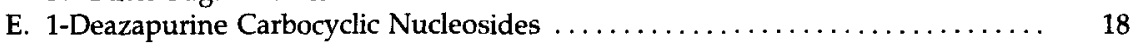

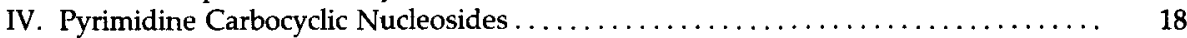

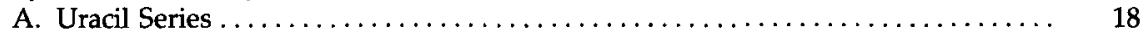

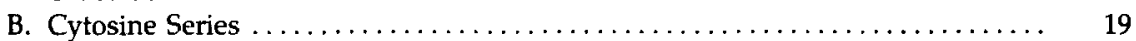

V. Cyclopentenyl Nucleosides: The Neplanocins $\ldots \ldots \ldots \ldots \ldots \ldots \ldots \ldots \ldots \ldots \ldots . \ldots \ldots \ldots \ldots$

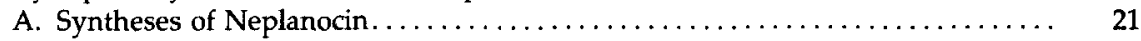

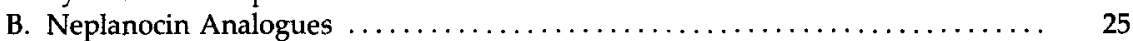

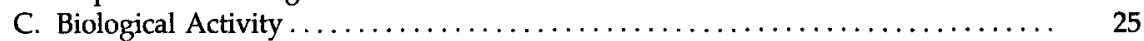

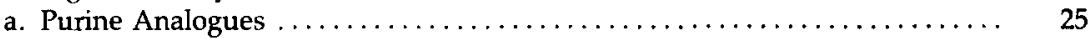

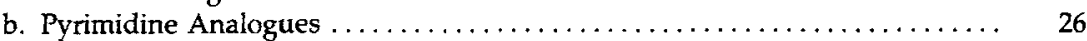

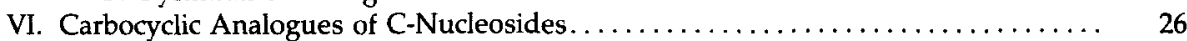

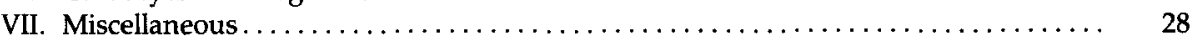

VIII. Carbocyclic Nucleosides and Enzymatic Methylation Reactions . . . . . . . . . 30

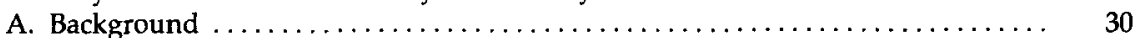

B. Mechanism of Adenosylhomocysteine Hydrolase (AdoHcy-ase) . . . . . . . . 31

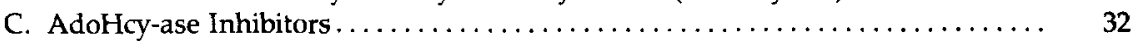

D. Mechanisms of Action of AdoHcy-ase Inhibitors $\ldots \ldots \ldots \ldots \ldots \ldots \ldots \ldots, 34$

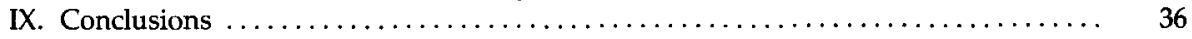

\section{INTRODUCTION}

The term carbocyclic nucleoside is used to describe a group of compounds structurally analogous to natural and synthetic nucleosides in which the furanose oxygen has been replaced by a methylene group. This transformation, therefore, changes the furanose ring into a cyclopentane. It is perhaps more

Medicinal Research Reviews, Vol. 6, No. 1, 1-40 (1986)

(C1986 by John Wiley \& Sons, Inc. 
correct to refer to these compounds as carbocyclic nucleoside isosteres because, strictly speaking, they are not nucleosides. Carbocyclic nucleosides, however, is a convenient term because these compounds undoubtedly exert their biological activity by mimicking the parent nucleosides. Consistent with the presence of the carbocyclic ring they are not subject to the action of nucleoside phosphorylases and hydrolases that cleave normal nucleosides. Conformationally, however, the expected similarity in bond lengths and bond angles between the tetrahydrofuran and cyclopentane rings allow these analogues to behave as substrates or inhibitors of the enzymes that activate and interconvert nucleosides and nucleotides in living cells. As a result of this likeness, many of these compounds are endowed with an interesting range of biological activities, especially in the areas of antiviral and anticancer chemotherapy. The majority of carbocyclic nucleosides known to date are of synthetic origin but nature has provided two of the most active compounds, aristeromycin (35a) and neplanocin-A (83). Although, to our knowledge, no comprehensive review on carbocyclic nucleosides has appeared in the literature, several publications have addressed this topic as a subcategory in sufficient detail to be considered as short reviews. ${ }^{1-3}$

The present review will encompass a discussion of both the chemistry and the biological properties of this unique group of compounds with special emphasis on those in which the structure resembles more closely that of conventional nucleosides.

A word of caution in relation to the nomenclature of these compounds is appropriate at this point. Throughout the literature, carbocyclic nucleosides are identified with a capital letter " $\mathrm{C}$ " followed by the name, or abbreviated name, of the corresponding nucleoside isostere (i.e., C-adenosine or C-Ado). This notation will be used throughout this article and ought not to be confused with that describing carbon nucleosides which, as a group, are referred to as C-nucleosides. In addition, carbocyclic nucleosides will be identified in this article with the same numbering system used in the description of their nucleosides isosteres.

\section{THE CHEMISTRY OF CARBOCYCLIC NUCLEOSIDES}

\section{A. General Discussion}

Several carbocyclic nucleosides were conceived and synthesized by medicinal chemists prior to the isolation of the carbocyclic adenosine prototype

Victor E. Marquez was born in 1943 in Caracas, Venezuela. He received a B.S. in Pharmacy from the Universidad Central de Venezuela in 1966 and later in 1970 a Ph.D. in Medicinal Chemistry from the University of Michigan. After spending 1 year as a postdoctoral fellow at the National Cancer Institute, NIH, and 5 years as Director of Research of Laboratorios Cosmos in Caracas, he returned to the NCI to his present position of Visiting Scientist. His current research interests involve the design and synthesis of nucleoside antitumor drugs based on mechanistic considerations. He has published over 40 research articles and has 5 patents.

Mu-Ill Lim received a B.S. from Kangwon National University in Korea in 1967. After receiving a Ph.D. in Synthetic Organic Chemistry from McGill University in 1976, and spending 6 years at Memorial Sloan-Kettering Cancer Center in New York, he joined the National Cancer Institute (NCI) as a Cancer Expert in 1982. His major research interest deals with the synthesis of biologically active molecules, particularly in the area of nucleoside chemistry. Since 1984 he joined Clairol Inc., in Stamford, CT. 
aristeromycin from natural sources. ${ }^{4-12}$ Some of the initially synthesized compounds were simple cyclopentyl substituted bases, ${ }^{11,12}$ but others included true isosteres of thymidine (C-Thy, 57b) and adenosine (C-Ado, 35a, or ( \pm )aristeromycin). ${ }^{9,10}$ The first reported synthesis of C-Thy, ${ }^{8}$ however, was found to be in error but the correct compound was later prepared. ${ }^{13-15}$ Most current synthetic approaches begin with the construction of the base from a functionalized cyclopentylamine (vide infra) which with very few exceptions is obtained as a racemic mixture. Consequently, most of the reported synthetic carbocyclic nucleosides are racemates. Recently, however, a long overdue enantioselective synthesis of aristeromycin has been finally achieved ${ }^{16,17}$ and of the three total synthesis of neplanocin A reported in 1983, two are enantioselective. ${ }^{16-19}$

\section{B. Synthesis of Carbocyclic Ribofuranosylamine (C-rib- $\mathbf{N H}_{\mathbf{2}}$ )}

The basic strategy in the synthesis of carbocyclic nucleosides has remained substantially unchanged since Shealy's original work, ${ }^{9,10}$ It involved: (1) synthesis of the carbocyclic ribofuranosylamine $6\left(\mathrm{C}-\mathrm{rib}-\mathrm{NH}_{2}\right.$, Figure 1), and (2) construction of the purine or pyrimidine ring from this amine by well established procedures in nucleoside chemistry. The other syntheses that followed differed mainly in the novelty and efficiency of producing the desired C-rib$\mathrm{NH}_{2}$ with the correct stereochemical disposition of substituents. Figure 1
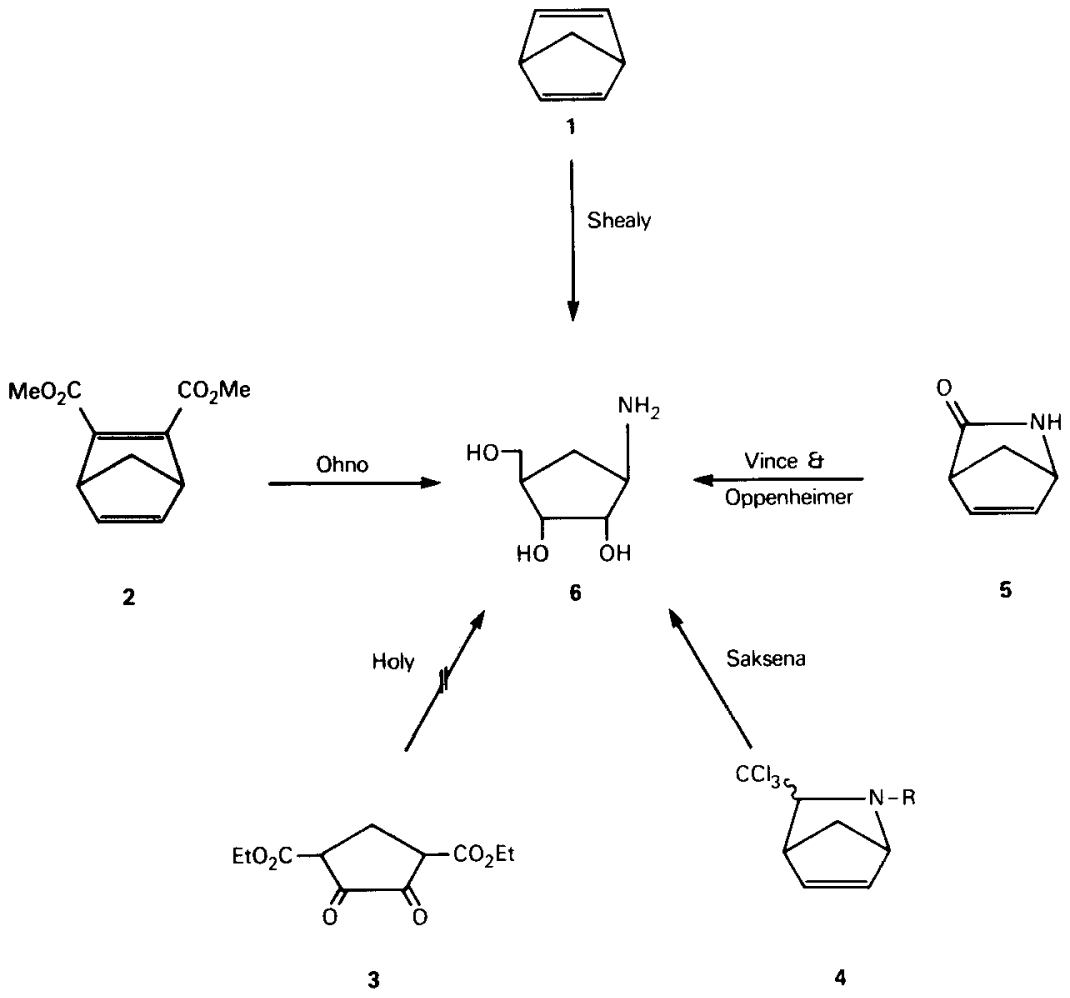

Figure 1. Synopsis of the different approaches to C-rib- $\mathrm{NH}_{2}$. 


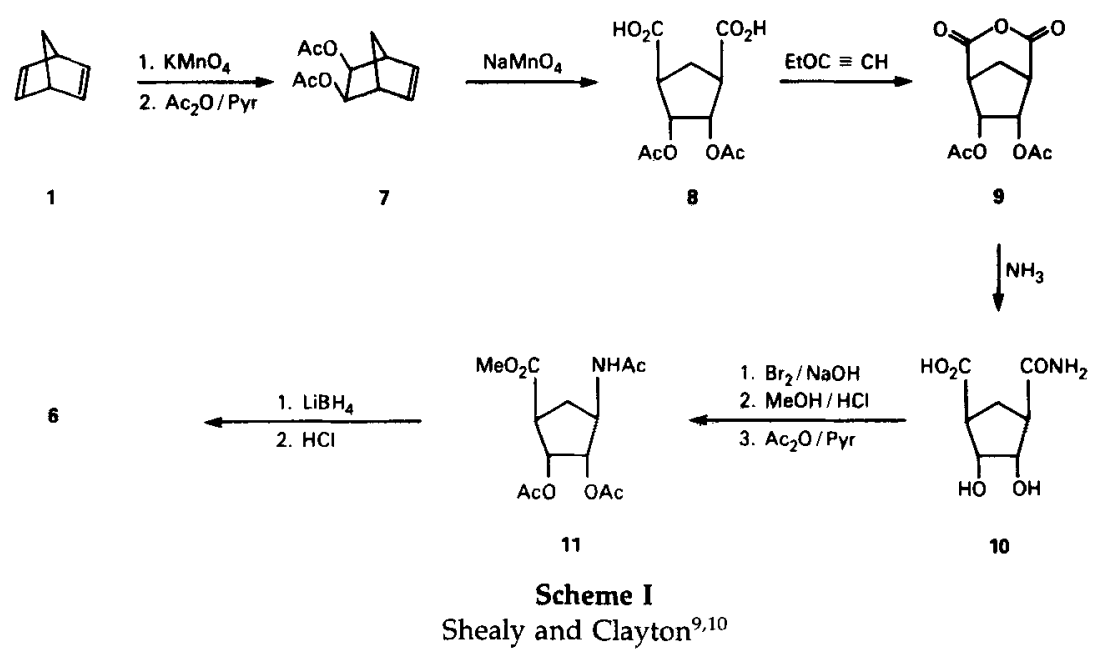

depicts a summary of the five different approaches to $\mathrm{C}$-rib- $\mathrm{NH}_{2}$ that have been reported thus far. $9,10,17,20-24$

With the exception of Holy's approach, ${ }^{20,21}$ all the syntheses utilized a rigid bicyclo[2.2.1] heptene system which allowed for better control of the stereochemistry of incoming substituents in subsequent reactions. When norbornadienes 1 and 2 were used as starting materials, the extra carbon atom in the molecule was replaced by the required amino function via a Hoffman rearrangement of a carboxylic acid amide generated after ozonolysis of one of the double bonds. Later, in an effort to overcome the use of the Hoffmann reaction, azabicyclo[2.2.1] heptene systems 4 and 5, which already contain a latent amine functionality, permitted a more efficient generation of C-rib- $\mathrm{NH}_{2}$ (Vince's and Saksena's methods). ${ }^{22-24}$ Use of an enzyme in the hydrolysis of meso diester 2 yielded an optically active half-ester from which the enantiomerically pure C-ribo- $\mathrm{NH}_{2}$ was obtained in Ohno's synthesis. ${ }^{17}$ Conversely, lack of a reagent capable of discriminating between symmetric groups in Shealy's method led to the desired amine only in its racemic form. ${ }^{9,10}$ Finally, in Holy's approach, an attempt was made to convert cyclopentanedione 3 to racemic C-rib- $\mathrm{NH}_{2} \cdot{ }^{20,21}$ It is questionable, however, that the correct compound was obtained due to the differences between a putative C-Ado prepared from 3, and samples of authentic (-)-aristeromycin and synthetic C-Ado (35a), obtained by other methods. ${ }^{25} \mathrm{~A}$ brief discussion of these syntheses follows: Cis-hydroxylation of 2,5-norbornadiene 1 followed by acetylation occurred stereospecifically producing the expected exo adduct diacetate 7 . Oxidative

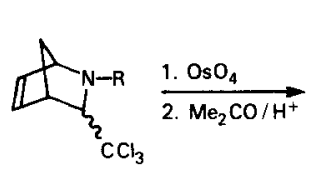

4a, $R=T s$

b. $\mathrm{R}=\mathrm{CO}_{2} \mathrm{Et}$

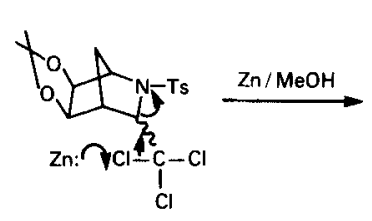

12

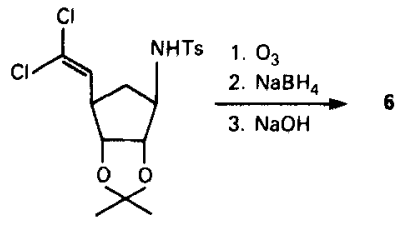

13 


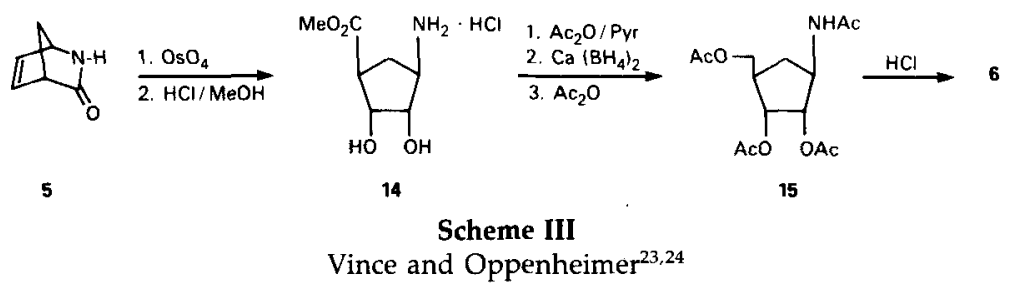

cleavage of the double bond led to diacid 8 , which was dehydrated to the anhydride 9. After opening the anhydride with ammonia, the resulting half amide 10 was subjected to the Hoffmann reaction, esterification, and reacetylation to give the triacetate 11. From the opening of the anhydride 9 an enantiomeric pair was generated and therefore all cyclopentyl derivatives obtained beyond this point are racemic (only one enantiomer is depicted). Reduction of the methyl ester and removal of the acetyl groups resulted in the formation of racemic C-ribo- $\mathrm{NH}_{2}(6)$.

In 1980 Saksena reported the synthesis of $( \pm)$ C-Ado starting with racemic 2-azabicyclo[2.2.1] heptenes $\mathbf{4 a}$ and $\mathbf{4 b}$ which had been previously obtained in excellent yields. ${ }^{21,22}$ After catalytic osmylation of $4 a$ and formation of the acetonide 12, a key reductive ring opening with activated zinc afforded alkene 13. Sequential ozonolysis, reduction, and hydrolysis, afforded the isopropylidene derivative of the target amine 6 . The yields were inferior when $4 b$ was used as the starting material.

The stable ( \pm )-2-azabicyclo[2.2.1] hept-5-ene-3-one (5) prepared earlier by Jagt and Van Leusen ${ }^{26}$ was used in several instances by Vince and Daluge since 1976 to prepare various carbocyclic nucleosides and aminonucleosides. ${ }^{27-30} \mathrm{How}$ ever, it was only in 1981 that they reported the direct osmylation of 5 which gave stereoselectively compound 14 after methanolysis of the lactam ring. ${ }^{23}$ When osmylation was performed earlier on the ring-opened hydrolyzed product of 5 , regioselectivity was lost and a mixture of isomers was produced. ${ }^{30}$ From 14, acetylation, reduction, and reacetylation, gave the tetraacetate $\mathbf{1 5}$ from which racemic C-rib- $\mathrm{NH}_{2}(6)$ was obtained. In the same year Oppenheimer and Kam
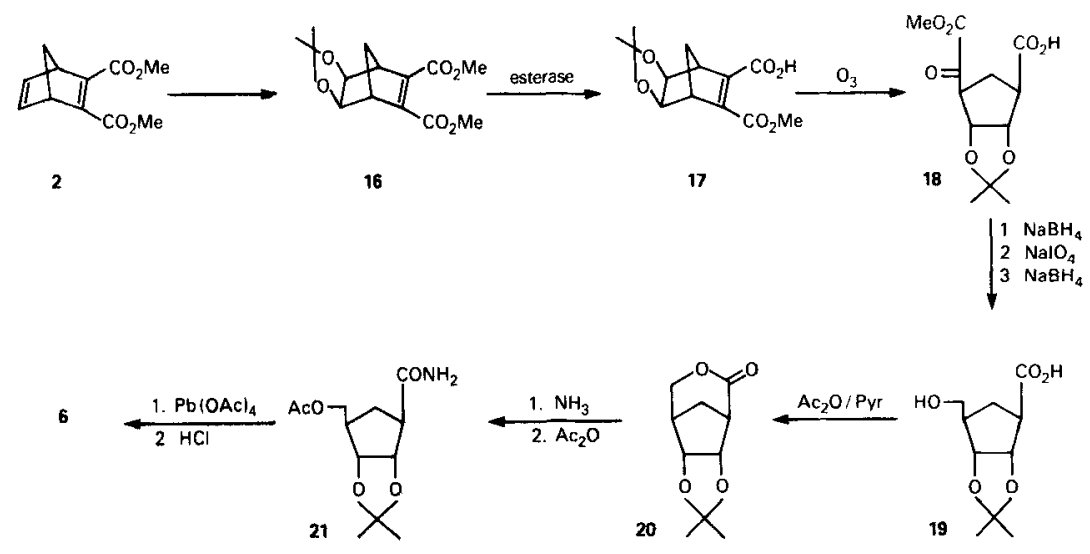

Scheme IV

Ohno et al. ${ }^{16,17}$ 
independently reported a nearly identical procedure which employed $\mathrm{KMnO}_{4}$ as an efficient cis-hydroxylating reagent. ${ }^{24}$

In a similar fashion as performed for the enantioselective synthesis of $\mathrm{C}$ - and $\mathrm{N}$-nucleosides, which started with a non-carbohydrate moiety, ${ }^{31}$ Ohno's group succeeded in producing optically active C-ribo- $\mathrm{NH}_{2}$. Pig liver esteràse asymmetrically hydrolyzed the known mesodiester $16,{ }^{32}$ to give the asymmetric acid 17. This acid was transformed into ketoacid $\mathbf{1 8}$ after a decarboxylative ozonolysis; and, following the successive treatment of $\mathbf{1 8}$ in a sequence which involved borohydride reduction, periodate cleavage of the vicinal glycol, and a second borohydride reduction, the hydroxyacid 19 was obtained. Lactonization of 19 followed by lactone opening with ammonia and acetylation, afforded amide 21. This compound was subjected to a Hoffmann reaction with $\mathrm{Pb}(\mathrm{OAc})_{4}$ which led to the target cycolpentylamine 6 after removal of the protective groups. The absolute configuration of 6 was shown to be identical to that of ribose as demonstrated by the fact that natural (-)-aristeromycin was obtained from it.

\section{General Methods of Aglycone Synthesis}

Among the various synthetic approaches to purines and pyrimidines only a few methods have been used in carbocyclic nucleoside chemistry, mainly because of the early commitment to the synthesis via the cyclopentylamine.

\section{a. Purines}

The time-honored route inspired in the Traube synthesis ${ }^{33}$ has been used to convert the carbocyclic amine $\left(\mathrm{R}-\mathrm{NH}_{2}\right)$ to the corresponding pyrimidylaminocyclopentane derivative $\mathbf{2 3}$ which is then followed by completion of the pyrrole, imidazole, or triazole ring, to give the corresponding purine carbocyclic nucleoside 24 (Scheme V). The reactive 6-chloro substituent allows replacement with ammonia or water to give the adenine and hypoxanthine analogues (25), respectively. Completion of the bicyclic system varies accordingly: it consists of (1) a spontaneous acid-catalyzed cyclization from $23(X=N$, $\left.\mathrm{Y}=\mathrm{CH}_{2} \mathrm{CH}(\mathrm{OEt})_{2}\right)$ in the case of the 7-deazapurine system; (2) formation of the imidazole ring from $23\left(\mathrm{X}=\mathrm{N}\right.$, or $\left.\mathrm{X}=\mathrm{CH}, \mathrm{Y}=\mathrm{NH}_{2}\right)$ after treatment with an activated one-carbon reagent (e.g. triethylorthoformate); or, (3) diazotization of the primary aromatic amine in $23\left(X=N, Y=\mathrm{NH}_{2}\right)$ to give the

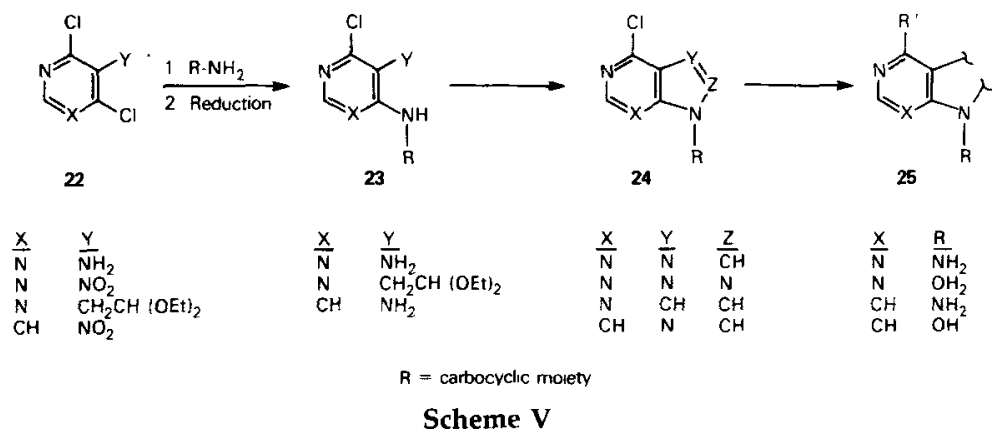




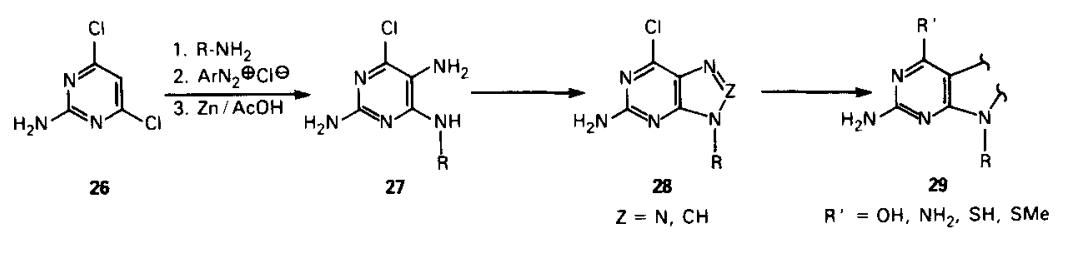

$\mathrm{R}=$ carbocyclic motety

Scheme VI

8-azapurine analogue. The compounds prepared by these procedures are listed in Table I.

The carbocyclic guanine and 2,6-diaminopurine analogues were obtained similarly as shown in Scheme VI. In this instance, formation of the pyrimidylaminocyclopentane derivative was followed by a phenyldiazo insertion and reduction with zinc, to afford the additional amino group in 27 necessary for the completion of the bicyclic system.

\section{b. Pyrimidines}

With the exception of first attempt to prepare the thymidine analogue (CThy, $\mathbf{5 7 b})^{8}$ which was later found to have given an isomeric product distinct from C-Thy, ${ }^{15}$ all reported syntheses of carbocyclic pyrimidines have made use of preformed carbocyclic amines as starting materials. The procedures apply the general methodology for the synthesis of uracil and thymine as developed earlier by Shaw and Warrener. ${ }^{34-36}$ Isocyanate $30\left(R^{\prime}=\mathrm{Me}\right.$ or Et, $\mathrm{X}=\mathrm{H}$ or $\mathrm{Me}$ ) was reacted with carbocyclic amine $\left(\mathrm{R}^{-\mathrm{NH}_{2}}\right)$ to give an intermediate acryloylurea 32 which was then cyclized in the presence of concentrated ammonia, or with acid catalysts, to give the uracil $(33, X=H)$ or thymine (33, $\mathrm{X}=\mathrm{CH}_{3}$ ) analogue (Scheme VII). Alternatively, the same result was obtained by reacting the carbocyclic amine with 3-ethoxy-N,2bis(ethoxycarbonyl)acrylamide (31) to give the 5-carboethoxyuracil (33, $\mathrm{X}=\mathrm{CO}_{2} \mathrm{Et}$ ). This substituent was later removed by hydrolysis and decarboxylation. The generated unsubstituted carbocyclic uridine derivatives (33, $\mathrm{X}=\mathrm{H}$ ) were amenable to direct halogenation at C-5 and the halogen later displaced by a host of nucleophiles to produce a number of 5 -substituted uridine analogues.

Transformation of the uracil ring into cytosine required conversion of the cyclic amide in 33 to the 4-chloropyrimidine $(34, \mathrm{X}=\mathrm{Cl}$ ) which reacted with ammonia to give $34\left(X=\mathrm{NH}_{2}\right)$. Alternatively, thiation of the uridine analogue 33 to the corresponding 4-thiouracil derivative, followed by methylation and ammonolysis, produced identical results. The reported carbocyclic uridine and cytidine derivatives are listed in Table II.

\section{Purine Carbocyclic Nucleosides.}

\section{A. Purine Carbocyclic Nucleosides.}

This group includes compounds with an intact imidazo[4,5-d]pyrimidine (purine) ring system bearing different 9-cyclopentyl substituents that mimick the several known sugar moieties of the corresponding nucleoside counter- 
Table I.

Carbocyclic Purine Nucleosides

\begin{tabular}{|c|c|c|c|c|c|}
\hline$\underline{\mathbf{s}}$ & Compound No. & $\underline{x}$ & $\underline{y}$ & $\underline{\mathbf{z}}$ & Ref. \\
\hline \multirow{16}{*}{ HO } & 36a (C-Ado, aristeromycin) & $\mathrm{NH}_{2}$ & H & $H$ & $4-6,9,10,16,17,22$ \\
\hline & b & $\mathrm{Cl}^{*}$ & $\mathrm{H}$ & $H$ & $9,10,37$ \\
\hline & c & $\mathrm{NHMe}$ & $\mathrm{H}$ & H & 37 \\
\hline & $d(C-\operatorname{lno})$ & $\mathrm{OH}$ & $\mathrm{H}$ & $H$ & $10,37,38$ \\
\hline & e & $\mathrm{OMe}$ & $H$ & $H$ & 37 \\
\hline & $f$ & $\mathrm{NHOH}$ & $\mathrm{H}$ & H & 37 \\
\hline & $\mathbf{g}$ & SH & H & $\mathrm{H}$ & $10,37,38$ \\
\hline & $\mathrm{h}$ & SMe & H & H & 10,38 \\
\hline & $\mathbf{i}$ & $\mathrm{NH}_{2}$ & $\mathrm{NH}_{2}$ & H & 39 \\
\hline & $j$ & $\mathrm{Cl}$ & $\mathrm{NH}_{2}$ & H & 39 \\
\hline & k & NHMe & $\mathrm{NH}_{2}$ & H & 39 \\
\hline & I (C-Gua) & $\mathrm{OH}$ & $\mathrm{NH}_{2}$ & $\mathrm{H}$ & 39,40 \\
\hline & $\mathbf{m}$ & SH & $\mathrm{NH}_{2}$ & $\mathrm{H}$ & 39 \\
\hline & $n$ & SMe & $\mathrm{NH}_{2}$ & $\mathrm{H}$ & 39 \\
\hline & 0 & $\mathrm{NH}_{2}$ & $\mathrm{H}^{2}$ & Br & 38 \\
\hline & $\mathbf{p}$ & $\mathrm{NH}_{2}^{-}$ & H & $\mathrm{OH}$ & 38 \\
\hline \multirow{3}{*}{ 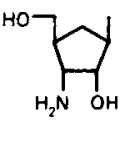 } & 36a & $\mathrm{NH}_{2}$ & H & H & 27,29 \\
\hline & b & $\mathrm{NMe}_{2}$ & H & H & 27,29 \\
\hline & 37a & $\mathrm{NH}_{2}$ & $H$ & $H$ & 38,41 \\
\hline \multirow{5}{*}{$\overbrace{H O}$} & b & $\mathrm{Cl}^{2}$ & H & $H$ & 41 \\
\hline & c & $\mathrm{cl}$ & $\mathrm{NH}_{2}$ & H & 42 \\
\hline & d & $\mathrm{OH}$ & $\mathrm{NH}_{2}$ & $\mathrm{H}$ & 42 \\
\hline & - & SH & $\mathrm{NH}_{2}^{+}$ & $\mathrm{H}$ & 42 \\
\hline & $\mathbf{t}$ & $\mathrm{NH}_{2}$ & $\mathrm{NH}_{2}$ & H & 42 \\
\hline \multirow{4}{*}{$\overbrace{O H}$} & 36 & $\mathrm{NH}_{2}$ & $\mathrm{H}$ & H & 38,41 \\
\hline & b & $\mathrm{Cl}$ & $\mathrm{H}$ & H & 41 \\
\hline & 39a (C-ara-A) & $\mathrm{NH}_{2}$ & $H$ & $\mathrm{H}$ & 28 \\
\hline & b & $\mathrm{Cl}$ & $H$ & $H$ & 28 \\
\hline \multirow{3}{*}{ HO HOY } & c & SH & $\mathrm{H}$ & $H$ & 43 \\
\hline & d & SMe & $\mathrm{H}$ & H & 43 \\
\hline & $:$ & $\mathrm{NMe}_{2}$ & $\mathrm{H}$ & H & 43 \\
\hline \multirow[t]{3}{*}{ no } & 1 & $\mathrm{NH}_{2}$ & $\mathrm{NH}_{2}$ & H & 44 \\
\hline & g (C-ara-Gua) & $\mathrm{OH}$ & $\mathrm{NH}_{2}$ & H & 44 \\
\hline & h & $\mathrm{Cl}$ & $\mathrm{NH}_{2}$ & $H$ & 44 \\
\hline HOTHOV & 40 & $\mathrm{NH}_{2}$ & $\mathrm{H}$ & H & 27,29 \\
\hline \multicolumn{6}{|l|}{$\mathrm{H}_{2} \mathrm{~N}$} \\
\hline \multirow{2}{*}{ OHOH } & $41 a$ & $\mathrm{NH}_{2}$ & $\mathrm{H}$ & H & 45 \\
\hline & b & $\mathrm{Cl}$ & $\mathrm{H}$ & H & 45 \\
\hline \multirow{3}{*}{ HO Hổ } & $42 a$ & $\mathrm{NH}_{2}$ & $\mathrm{H}$ & $H$ & 30 \\
\hline & b & $\mathrm{Cl}^{2}$ & H & H & 30 \\
\hline & $43 a$ & $\mathrm{Cl}$ & $H$ & $H$ & 12 \\
\hline \multirow{5}{*}{ Ho } & b & $\mathrm{OH}$ & $\mathrm{H}$ & H & 12 \\
\hline & c & SH & $H$ & $\mathrm{H}$ & 12 \\
\hline & d & $\mathrm{NH}_{2}$ & $H$ & $\mathrm{H}$ & 12 \\
\hline & e & NHMe & $\mathrm{H}$ & H & 12 \\
\hline & $f$ & $\mathrm{NMe}_{2}$ & $H$ & H & 12 \\
\hline
\end{tabular}


Table I.

(Continued)
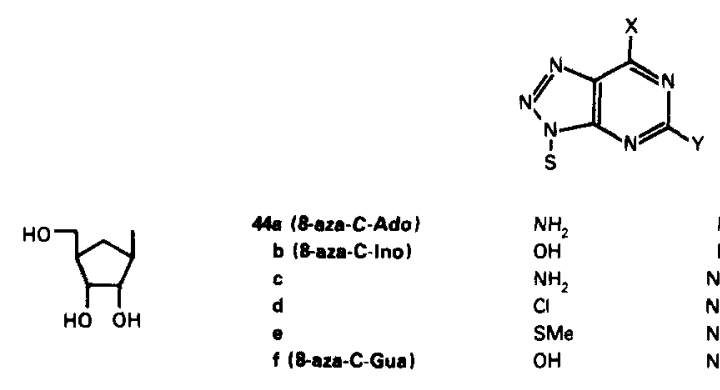

$\begin{array}{lll}\mathrm{NH}_{2} & \mathrm{H} & 46,47 \\ \mathrm{OH} & \mathrm{H} & 47 \\ \mathrm{NH}_{2} & \mathrm{NH}_{2} & 39 \\ \mathrm{Cl} & \mathrm{NH}_{2} & 39,40 \\ \mathrm{SMe} & \mathrm{NH}_{2} & 39 \\ \mathrm{OH} & \mathrm{NH}_{2} & 39,40\end{array}$<smiles>CC1CC2CC(CO)(C1)C2O</smiles>
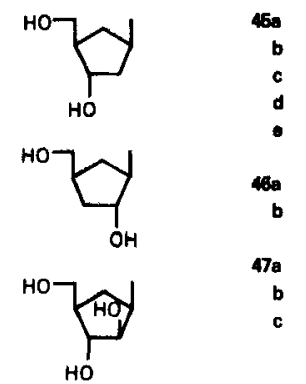

$47 a$
$b$

HOF

46

107

$\mathrm{NH}_{2}$

$\mathrm{OH}$

$\mathrm{OH}$

$\mathrm{H}$
$\mathrm{H}$
$\mathrm{NH}_{2}$
$\mathrm{NH}_{2}$
$\mathrm{NH}_{2}$

4

47
47
42
42
42

47
47
44
44
44

$\mathrm{NH}_{2}$

Nith

$\mathrm{NH}_{2}$
$\mathrm{OH}$

H

$\mathrm{OH}$

$\mathrm{Cl}^{2}$

$\mathrm{NH}_{2}$

$\begin{array}{ll}\mathrm{NH}_{2} & \mathrm{H} \\ \mathrm{OH} & \mathrm{H}\end{array}$

30
30

$\mathrm{NH}_{2}$

$\mathrm{OH}_{2}$

4

47
47

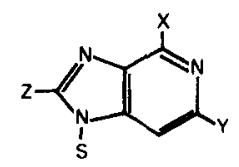

(1)

$50 a$
b
c

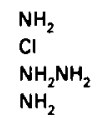

$\mathrm{NH}_{2}$
$\mathrm{Cl}$
$\mathrm{NH}_{2} \mathrm{NH}_{2}$
$\mathrm{NH}_{2}$

$\begin{array}{ll}H & H \\ H & H \\ H & H \\ H & H\end{array}$

48
48
48
48

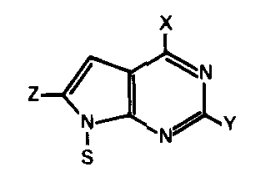

OH

$\mathrm{NH}_{2}$
$\mathrm{Cl}$
$\mathrm{NH}_{2}$
$\mathrm{Cl}$

$\mathrm{H}$
$\mathrm{H}$
$\mathrm{H}$

$\begin{array}{ll}H & 49 \\ H & 49 \\ \text { Me } & 50 \\ \text { Me } & 50\end{array}$

HO

$\mathrm{NH}_{2}$

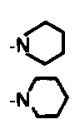

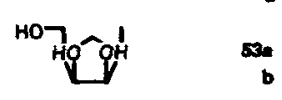

507

$\mathrm{NH}_{2}$

$\mathrm{Cl}^{2}$

$\mathrm{NH}_{2}$

H

50,51

$\begin{array}{ll}\text { Me } & 50,51 \\ \text { Me } & 50,51\end{array}$

$\begin{array}{llll}H & M e & 51 \\ H & M e & 51\end{array}$

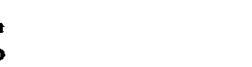

H

Me
Me

50,51

50,51

54 
Table I.

(Continued)

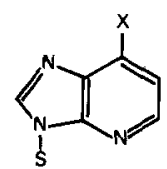

MO

56

$\mathrm{NH}_{2}$

53

Table II

Carbocyclic Pyrimidine Nucleosides
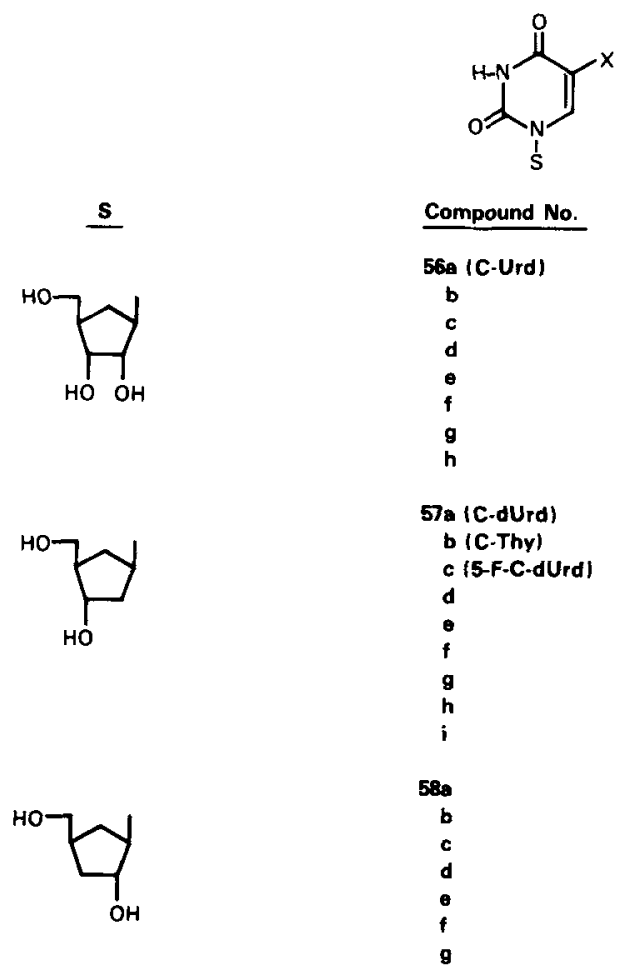

\section{7a (c-dUrd)}

b (C-Thy)

c (5-F-C-dUrd)

$d$

-

g

h

i

HOT

59

H

Ref.

HOO

60

X

65

H

$\mathrm{CH}_{3}$

$\mathrm{Br}$

I

$\mathrm{NH}_{2}$

$\mathrm{NHCH}_{3}$

$\mathrm{CH}_{2} \mathrm{OH}$

$\mathrm{H}$

$\mathrm{CH}_{3}$

Br

1

$\mathrm{NH}_{2}$

$\mathrm{NHCH}_{3}$

$\mathrm{N}\left(\mathrm{CH}_{3}\right)$

$\mathrm{H}$
$\mathrm{CH}_{3}$
$\mathrm{~F}$
$\mathrm{Br}$
$\mathrm{I}$
$\mathrm{NH}_{2}$
$\mathrm{NHCH}_{3}$

13,66

66

66

66

66

66

66

65,66

13-15,66

66,67

66

66

66

66

66

65,66

$13,15,66$

66,67

66

66

66

66

68

OH

61

$\mathrm{CH}_{3}$

15

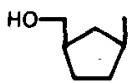

62

$\mathrm{CH}_{3}$

15 
Table II.

(Continued)

(C) (C-Cyt)

parts. Other variations include substitutions at positions 6,2 , and 8 which are indicated as $\mathrm{X}, \mathrm{Y}$, and $\mathrm{Z}$ (Table 1 ).

\section{a. Ribose Isosteres}

The first compound of this class that was synthesized was the carbocyclic analogue of adenosine (C-Ado, 35a) which was obtained as a racemate. ${ }^{9,10}$ Shortly after, the pure enantiomer was isolated from the culture filtrate of Streptomyces citricolor and confirmed to be $\left(1^{\prime} R, 2^{\prime} R, 3^{\prime} R, 4^{\prime} R\right)-9\left[\beta-D-2^{\prime} \alpha, 3^{\prime} \alpha-\right.$ dihydroxy- $4^{\prime}-\beta$ (hydroxymethyl)cyclopentyl]adenine or $(-)$-aristeromycin.$^{5,6}$ Several other syntheses of $C$-Ado have been reported including a recent enantioselective preparation. ${ }^{16,17,22}$ As expected, C-Ado displayed a wide range of biological activities. ${ }^{54-61 a}$ It was highly cytotoxic to both H.Ep.-2 and L1210 cells in culture, but it demonstrated poor selectivity towards the tumor cells in view of its inactivity in the mouse L1210 model system. ${ }^{10}$ At subtoxic concentrations it induced cell proliferation of quiescent normal cells, but in contrast, it inhibited growth in malignant cell lines. ${ }^{54 a}$ The primary toxic effects of C-Ado appear to be mainly derived from the corresponding nucleotide (CAMP) generated in cells containing adenosine kinase $\left(\mathrm{AK}^{+}\right) .{ }^{54}$ This metabolite has been synthesized chemically by selective phosphorylation of the $5^{\prime}$-hydroxyl group..$^{55}$ Like adenosine, C-Ado is also deaminated by adenosine deaminase (ADA), but its affinity for the enzyme is a hundredfold lower. ${ }^{54}$ No NAD metabolite derived form C-Ado has been detected and incorporation 


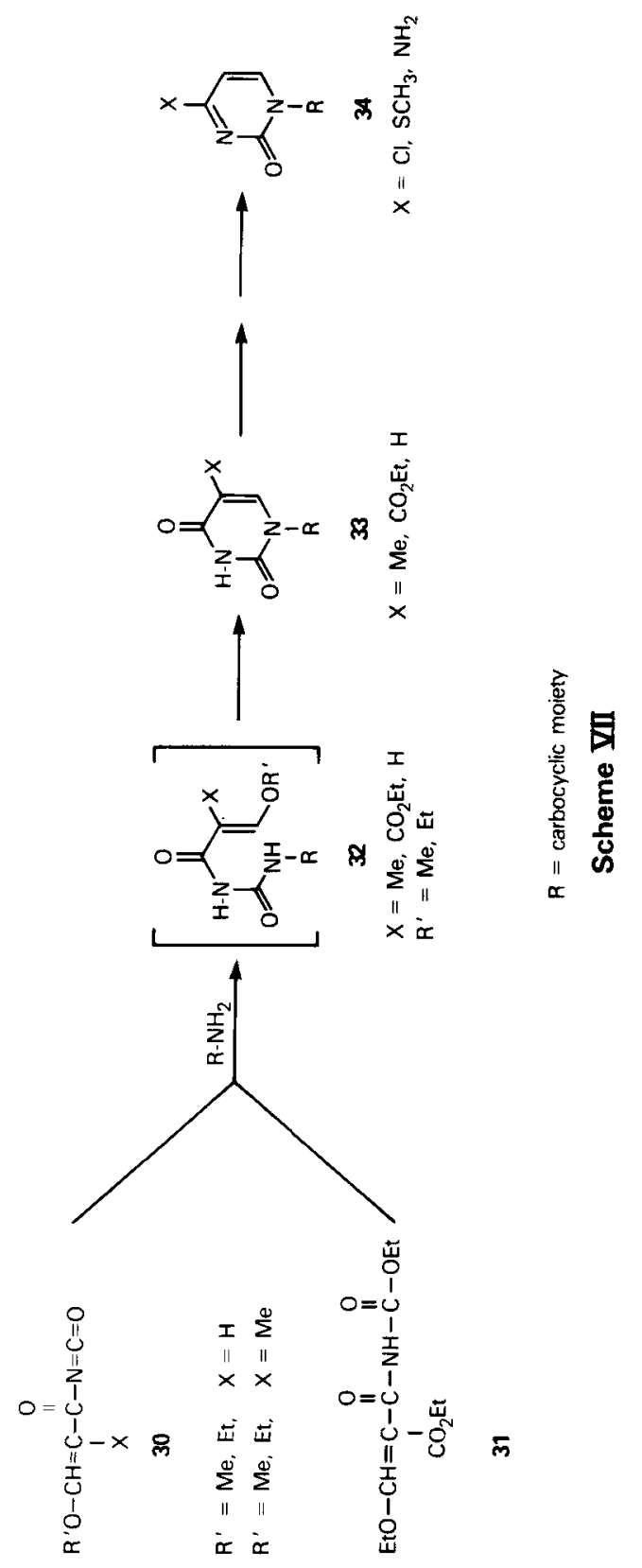


into RNA and DNA is negligible. Homopolymerization of the diphosphate (C-ADP) with E. coli polynucleotide phosphorylase was also negligible, but in the presence of $\mathrm{ADP}$ it was polymerized to polynucleotides containing various ratios of Ado and C-Ado. ${ }^{55 a} \mathrm{C}$-AMP could be further metabolized to the triphosphate (C-ATP) and a major metabolic effect appears to be the inhibition of utilization of guanine and hypoxanthine. ${ }^{56}$ Consistent with this observation, C-AMP has been recognized as a powerful inhibitor of GMP kinase $\left(K_{i}=12 \mu \mathrm{M}\right)$ which causes accumulation of GMP. This increased levels of GMP may be responsible for the growth inhibitory properties observed, since GMP is an end-product inhibitor of hypoxanthine(guanine)phosphoribosyl transferase (HGPRT). ${ }^{56}$ A recent reinvestigation of the metabolism of C-Ado in H.Ep.-2 and L1210 cells revealed that in addition to C-ATP, the corresponding carbocyclic guanosine triphosphate (C-GTP) was also formed. This metabolite was found to be the most effective known inhibitor of HGPRT. ${ }^{57}$ As expected, AK deficient cells $\left(\mathrm{AK}^{-}\right)$, which are unable to phosphorylate $\mathrm{C}$ Ado, showed some resistance to the drug after a short exposure. ${ }^{54,58,59}$ However, the $\mathrm{ID}_{50}$ for both $\mathrm{AK}^{+}$and $\mathrm{AK}^{-}$cells after prolonged exposure was very similar $(0.3-0.6 \mu \mathrm{M}){ }^{58}$ In $\mathrm{AK}^{+}$cells, therefore, rapid toxicity ensues after formation of C-AMP, C-ATP and C-GTP. In AK- cells, on the contrary, there is a slower process mediated by $\mathrm{C}$-Ado itself that does not require metabolic activation. Such delayed cytotoxicity is related to the inhibitory effect of CAdo on S-adenosylhomocysteine hydrolase (AdoHcy-ase) which will be discussed in Section VIII. C-Ado was also found to be a potent inhibitor of the growth of plant infecting bacteria and a moderate inhibitor of the growth of the protozoon Tetrahymena pyriformi $\mathrm{s}^{60,60 \mathrm{a}}$ Lastly, C-Ado showed no significant antiviral activity against $\mathrm{HSV}$, vaccinia, rhino, or influenza viruses. ${ }^{61}$

All other 6-substituted C-Ado analogues $(35 b-35 h)$ reported to date were also inactive against L1210 leukemia in mice, despite the fact that some of them (i.e. compounds 35b, 35c, and 35f) were cytotoxic to H.Ep.-2 cells in vitro. ${ }^{37}$ The corresponding carbocyclic inosine (C-Ino, 35d), although devoid of antitumor activity, showed comparable antiviral activity to that of ara-A against HSV (VR $=2.1) \cdot{ }^{61,61 \mathrm{~b}}$ In vivo, C-Ino results from the deamination of $\mathrm{C}$-Ado and is an obligatory intermediate in the metabolic conversion of $\mathrm{C}$ Ado to C-GMP. ${ }^{57}$ Other 6-substituted C-Ado analogues with good antiviral (HSV) activity were $35 \mathrm{e}$ and $35 \mathrm{~h} .{ }^{61}$ The transformation of the ribose moiety of 6-methylthiopurine ribonucleoside into the cyclopentyl moiety of $35 \mathrm{~h}$ resulted in loss of cytotoxicity, but endowed the compound with good antiviral activity which was lacking in the riboside. ${ }^{61}$ Simultaneous substitution at C6 and C-2 engendered the carbocyclic guanosine analogue (C-Gua, 351) and other 2-aminopurine derivatives. ${ }^{39,40} \mathrm{C}$-Gua was found neither cytotoxic to H.Ep.-2 in vitro, nor active against murine L1210 in vivo. ${ }^{39,40}$ The rest of the 2,6-disubstituted analogues (i.e. 35i-35n) were likewise inactive against L1210 in mice. ${ }^{39}$ On the other hand, the carbocyclic analogue of 2,6-diaminopurine ribofuranoside (35i) demonstrated superior activity to that of ara-A against HSV-1 and vaccinia virus (VR $=4.6$ ) and some of the other derivatives also displayed good antiviral activity (35j and $35 \mathbf{k})$. $^{39}$

C-Ado analogues substituted at $\mathrm{C}-8$ by either $\mathrm{Br}(350)$ or $\mathrm{OH}(35 \mathrm{p})$ have been reported but their biological activity is not known. ${ }^{38}$ 

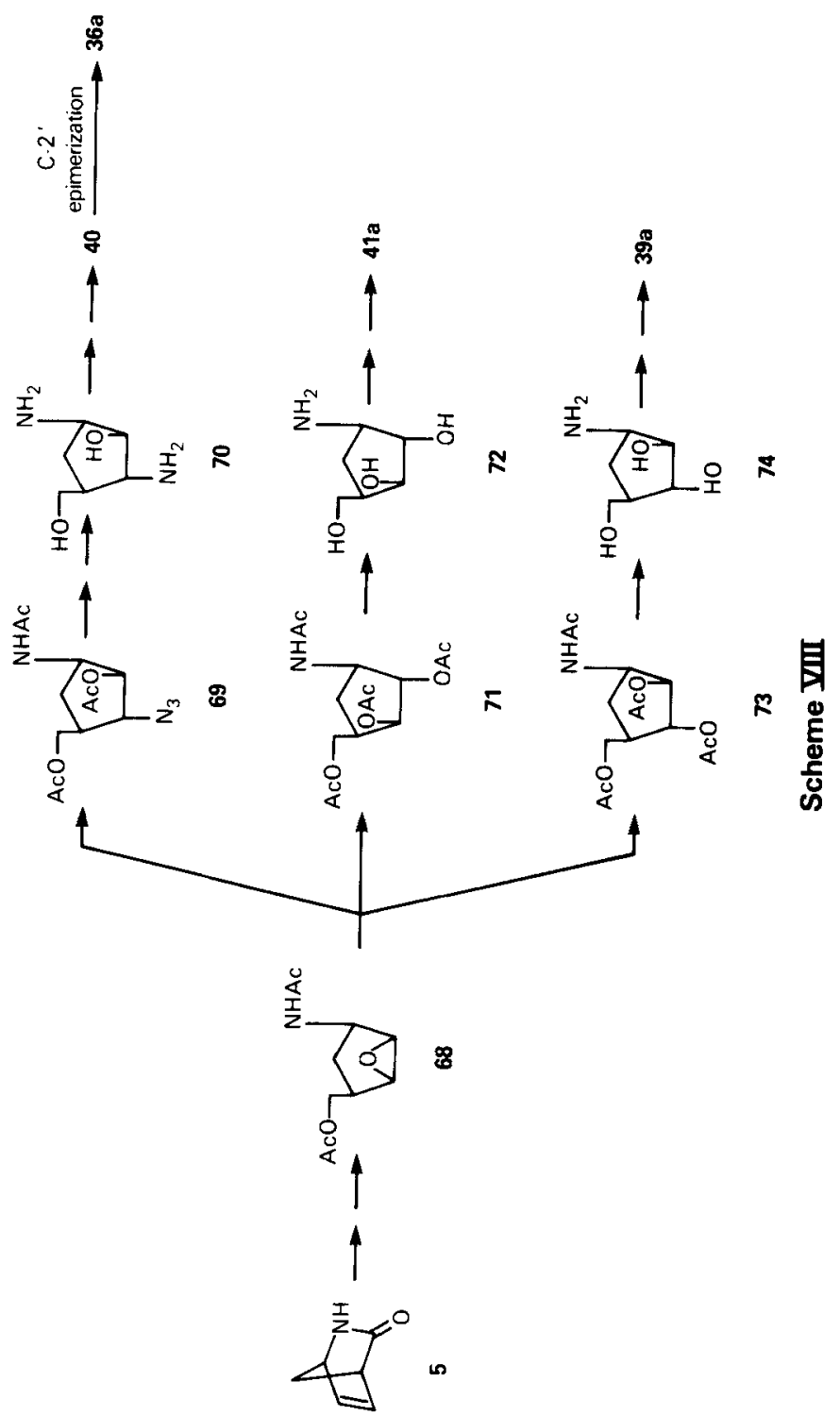


\section{b. Other Sugar Isosteres}

Replacement of the $3^{\prime}-\mathrm{OH}$ group by an amino group in the structure of CAdo generated the carbocyclic $3^{\prime}$-amino-3'-deoxy adenosine (36a) which showed good antiviral activity against $H S V-1(V R=2.1)$ and vaccinia $(V R=2.2){ }^{27,29}$ Such a replacement was performed by Daluge and Vince starting with the versatile 2-azabicyclo[2.2.1] hept-5-ene-3-one (5) already discussed in Section II-B. As shown in Scheme VIII, hydrolysis of this compound was followed by the regioselective formation of epoxide 68. This critical epoxide also served as the starting material for other carbocyclic sugar isosteres. ${ }^{27-29}$ Opening of the epoxide ring with sodium azide occurred predominantly at the position farthest away from the acetamido group to give 69, whereas hydrolysis and reacetylation gave a mixture of 71 and 73 . Reduction of the azide and anchimerically assisted hydrolysis of the acetamide group by the cis hydroxyl substituent gave the diamine $\mathbf{7 0}$. This compound was converted to $\mathbf{4 0}$ and finally to $36 \mathrm{a}$ after epimerization at $\mathrm{C}-2^{\prime}{ }^{27,29}$

Shealy and O'Dell converted exo-bicyclo[2.2.1]hept-5-en-2-ol to racemic mixtures of 4-amino-3-hydroxy and 4-amino-2-hydroxycyclopentanemethanol in the manner described for the carbocyclic ribofuranosylamine 6 (Scheme I) ${ }^{41,62}$ These amines served respectively as precursors for the carbocyclic analogues of $2^{\prime}$-deoxy and 3 -deoxyadenosine (37a and 38a). Alternatively, these compounds were accessed directly from (-)-aristeromycin after treatment with acetyl bromide. ${ }^{38}$ As shown in Scheme IX, bromide attack on the generated acetoxonium ion 75 produced $2^{\prime}$ and $3^{\prime}$-bromonucleosides 76 and 77 with inverted configuration. Hydrogenolysis of these halogenonucleosides accomplished the necessary dehalogenation to afford $2^{\prime}$ and $3^{\prime}$-deoxyaristeromycin (37a and 38a). ${ }^{38}$ No report on the biological activity of either $2^{\prime}$-deoxy or $3^{\prime}$-deoxy-C-Ado has appeared.

Recently, several 2'-deoxy carbocyclic nucleosides of 2-amino-6-substituted purines have been reported and the chemical methods of syntheses parallel those of the analogous carbocyclic ribofuranoside isosteres. ${ }^{42}$ These analogues (37c-f) are active against HSV-1 and even more potent against HSV-2 than the carbocyclic 5-substituted-2'-deoxyuridines (Section IV-A). Moreover, the deaminated products formed after reaction with adenosine deaminase (ADA)

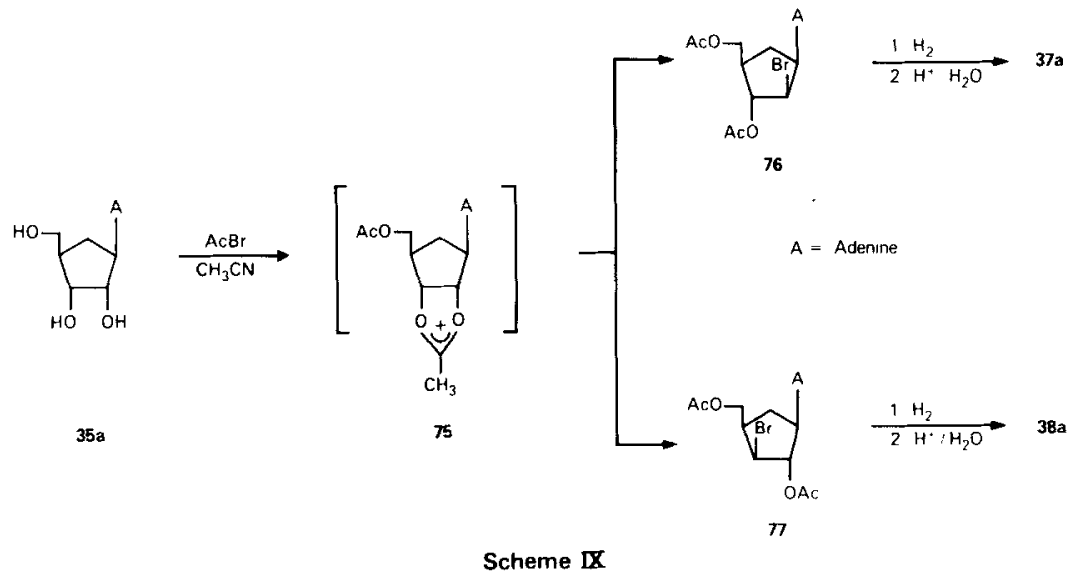

cheme $\mathbf{X}$ 
retained activity as opposed to the case of the ribofuranoside isostere $35 \mathbf{i}$ which after deamination produced the inactive guanosine derivative 351 . The compounds, however, were devoid of in vivo antitumor activity against murine L1210 leukemia. ${ }^{42}$

Two very useful modifications of the carbocyclic moiety have been the inversion of configuration of the 2'-hydroxyl and 3'-hydroxyl groups to give, respectively, the deaminase resistant arabinofuranosyl and xylofuranosyl carbocyclic isosteres $39 a$ and $41 a^{28,45}$ As reviewed in Scheme VIII, these compounds originated from the corresponding carbocyclic amines 72 and 74 obtained from hydrolysis of epoxide 68. C-ara-A (39a), in particular, has demonstrated antiviral activity against $\mathrm{HSV}$ and vaccinia virus (VR's $=1.5-3.5)^{28}$ and more recently its prodrug $5^{\prime}$-methoxyacetate exhibited significant efficacy in the topical treatment of genital infections by HSV-2. ${ }^{63}$ In addition, it demonstrated activity against the acyclovir-resistant variants deficient in DNA polymerase or thymidine kinase. ${ }^{63} \mathrm{~A}$ recent patent describing compounds 39a-e has appeared but only the activity of C-ara-A (cyclaradine, 39a) was reported. ${ }^{43}$ Both isosteres (C-ara-A and C-xylo-A) were cytotoxic to P388 mouse lymphoid leukemia cells, ${ }^{43,45}$ but no in vivo activity was evidenced. ${ }^{45}$

Another carbocyclic arabinoside analogue with good antiviral activity was the 2,6-diaminopurine analogue $39 f(V R=1.5) .{ }^{44}$ The carbocyclic riboside isostere $35 \mathrm{i}$, however, appears to be superior. ${ }^{39}$ Carbocyclic C-ara-Gua $(39 \mathrm{~g}$,) on the other hand, demonstrated good cytotoxicity against $\mathrm{P} 388$ cells in vitro at a concentration five times lower than that of $39 \mathrm{f}$, but lacked antiviral activity. ${ }^{44}$

A final modification of $2^{\prime}$ and $3^{\prime}$-hydroxyl groups in C-Ado included the simultaneous inversion of these groups as in the lyxo compound 42a. No biological data has been reported for this compound. ${ }^{30}$ The deletion of both $2^{\prime}$ and $3^{\prime}$-hydroxyl groups, resulting in compounds $43 \mathbf{a}-\mathbf{f}$, produced only weak inhibitors of ADA. ${ }^{12}$

\section{B. 8-Azapurine Carbocyclic Nucleosides}

This group includes carbocyclic analogues of 8-azapurine ribonucleosides with variations on the carbocyclic moiety typical of the nucleoside counterparts. Substituents on the 8-azapurine ring are at positions 2 and 6 (Table I).

\section{a. Ribose Isosteres}

The simplest member reported in this series is compound 44a (8-aza-CAdo $)^{46,47}$ which represents one of the few carbocyclic purine derivatives active in vivo against P388 (max ILS $68 \%$ at $100 \mathrm{mg} / \mathrm{Kg}$ qd 1-9) and L1210 (borderline activity) leukemias. The corresponding 8-azahypoxanthine analogue (8-azaC-Ino, $44 \mathbf{b}$ ) was devoid of antitumor activity both in vitro and in vivo, ${ }^{47}$ but, in agreement with the observed inverse relationship between antitumor and antiviral activities, it displayed good antiviral activity with VR's of 1.5 against HSV and 1.2 against vaccinia virus. ${ }^{61}$ Recently, the 8 -aza-C-Gua (44f) analogue, as well as compounds $44 c-e$, were evaluated as antiviral agents. ${ }^{39}$ Only the 8-aza-C-2,6-diamino analogue 44c demonstrated activity against HSV-1 $(\mathrm{VR}=1.4)$, but it was less potent than the carbocyclic 2,6-diaminopurine $35 i .{ }^{39}$ 8-Aza-C-Gua was devoid of cytotoxicity against H.Ep.-2 cells in vitro and was ineffective against L1210 in vivo. ${ }^{40}$ 


\section{b. Other Sugar Isosteres}

Typical variations of the sugar moiety represented by the 2 '-deoxy and 3 'deoxy analogues of 8-aza-C-Ado (45a and 46a) produced inactive compounds against L1210 leukemia suggesting that these compounds are not being phosphorylated intracellularly. ${ }^{47}$ The corresponding 2-amino-6-substituted-8-azaC-2'-deoxy analogues (45c-e) displayed antiviral activities against both HSV1 and HSV-2 which were superior to ara-A in VR value (4-5) and potency. ${ }^{42}$ In this case, deamination of $45 \mathrm{e}$ by ADA, generated an even more potent antiviral compound (45d). The carbocyclic arabinose isostere of 8-azaguanosine (8-aza-C-ara-Gua, 47a) was cytotoxic to P388 cells in vitro as was C-araGua and it was similarly devoid of antiviral activity. ${ }^{44}$ Conversely, the $2,6-$ diamino-8-aza-ara carbocyclic analogue $47 \mathrm{~b}$, displayed very low cytotoxicity to P388 cells and significant activity against HSV-1 with a VR of $1.3 .{ }^{44}$ Change of the carbocyclic moiety to the xylo configuration as in 8-aza-C-xylo-A,* produced a compound resistant to ADA deamination and with significant in vivo antitumor activity against P388 leukemia (ILS $126 \%$ at $50 \mathrm{mg} / \mathrm{Kg}$ on days 1 and 5). ${ }^{45}$ The activity of this compound varies with the schedule of administration but it is significant enough to deserve further investigation.

Finally, the simultaneous inversion of the 2 ' and $3^{\prime}$-hydroxyl groups that generated the carbocyclic lyxofuranosyl analogues $48 \mathrm{a}$ and $48 \mathrm{~b}$, plus the complete deletion of these hydroxyl groups altogether $(49 a, b)$, afforded compounds whose activities were not reported. ${ }^{30,47}$

\section{3-Deazapurine Carbocyclic Nucleosides}

The parent compound in this series is 3-deaza-C-Ado (50a) which was found to be a good antiviral agent against HSV-1, vaccinia virus, and HL-23 type virus. $^{48}$ The antiviral activity and potency against vaccinia (VR $=2.8$, $\left.\mathrm{MIC}_{50}=1.9 \mathrm{ug} / \mathrm{ml}\right)$ compared favorably with respect to that of ara-A $(\mathrm{VR}=1.2$, $\mathrm{MIC}_{50}=19.2 \mathrm{ug} / \mathrm{ml}$ ) but it was less potent than ara-A against HSV-1. In contrast to C-Ado, 3-deaza-C-Ado is neither deaminated by ADA nor phosphorylated by AK in L1210 cells. ${ }^{48}$ The relationship between its antiviral activity and inhibition of AdoHcy-ase will be discussed separately (Section VIII). Precursors and derivatives of 3-deaza-C-Ado are listed in Table I (50b-d).

\section{7-Deazapurine Carbocyclic Nucleosides}

\section{a. Ribose Isosteres}

The prototype of this series is 7-deaza-C-Ado (51a, Table I) which was recently reported together with its 6-chloro substituted precursor $(51 \mathrm{~b}) .{ }^{49}$ As expected, the compound was resistant to ADA in the same manner as the ribofuranoside isostere tubercidin (7-deazaadenosine) and it required phosphorylation to exert its cytotoxic effect. In in vivo tests it was toxic to mice but ineffective in prolonging the life of P388 infected mice. ${ }^{49}$ Its antiviral activity was also marginal. The 8-methyl analogue 51c has also been reported recently and likewise it was found neither cytotoxic to L1210 cells nor active against HSV $-1 .^{50}$

\footnotetext{
*This compound was inadvertently omitted from Table I. Its correct placement in this Table would be following compound 47 .
} 


\section{b. Other Sugar Isosteres}

The carbocyclic ara and lyxofuranosyl analogues $\mathbf{5 2 a - d}$ and $\mathbf{5 3 a} \mathbf{a} \mathbf{b}$ have been prepared and found inactive as antitumor or antiviral agents. ${ }^{50,51}$ Removal of both $2^{\prime}$ and $3^{\prime}$-hydroxyls gave 54 which was equally inactive against L1210 cells in vitro. ${ }^{52}$

\section{E. 1-Deazapurine Carbocyclic Nucleosides}

Only one compound in this group has been reported thus far and it is the corresponding 1-deazaaristeromycin (55, Table I). It was prepared in an analogous manner as $\mathrm{C}$-Ado starting with 4-amino-2-chloro-3-nitropyridine and C-rib- $\mathrm{NH}_{2}$ (See Scheme V). ${ }^{53}$ The compound was found to be a weak competitive inhibitor of ADA and a potent irreversible inhibitor of AdoHcy-ase with poor affinity for the receptor. ${ }^{53}$ No other biological data is yet available.

\section{PYRIMIDINE CARBOCYCLIC NUCLEOSIDES}

\section{A. Uracil Series}

This group includes all the cyclopentyl derivatives of substituted and unsubstituted 2,4-(1H,3H)pyrimidinediones that mimic the different pentofuranosyl nucleosides (Table II). Chronologically, the first compound described was the thymidine isostere C-Thy $(\mathbf{5 7 b})$ which was synthetically approached by the Prins reaction starting with known 1-(3-cyclopentenyl)thymidine (78). ${ }^{7,8}$

78<smiles>Cc1cn(C2CC=CC2)c(=O)[nH]c1=O</smiles>

79

A comparison of the product obtained through this reaction with authentic C-Thy, as prepared later by Shealy and O'Dell, ${ }^{13,14}$ demonstrated that the first sample had structure $79 .{ }^{15}$ The current approach to this class of compounds, including C-Thy, begins with a carbocyclic amine precursor (Scheme VII) as discussed earlier in Section II-C-b. With this approach the generation of anhydronucleosides $\mathbf{8 0}$ and $\mathbf{8 1}$ from $\mathrm{C}$-Thy further corroborated the correct disposition of the base on the carbocyclic moiety. ${ }^{15}$ Additionally, ${ }^{1} \mathrm{H}$ and ${ }^{13} \mathrm{C}-$ NMR studies confirmed the relative disposition of hydroxyl groups on the carbocyclic ring. ${ }^{13,15}$<smiles>Cc1cn(C23CC4CC(C2)C(CO)(C4)C3)c(=O)[nH]c1=O</smiles>

81<smiles>CC(=O)OC1CC2CC1COc1nc(=O)c(C)cn12</smiles> 
The carbocyclic uridine analogue (C-Urd, 56a) was first reported by Holy, ${ }^{20,64}$ but since the structure of his starting $\mathrm{C}$-rib- $\mathrm{NH}_{2}$ was later confirmed to be erroneous, ${ }^{25}$ the isolated compound was rather an isomer of C-Urd of yet unknown structure. ${ }^{2}$ The compound with the correct structure was prepared later by an analogous procedure used for the synthesis of C-Thy that started with authentic C-rib- $\mathrm{NH}_{2}(6),{ }^{65,66}$ The generality of Shealy's method permitted ready access to many carbocyclic sugar isosteres by simply starting with the appropriate aminocyclopentane (57-62). ${ }^{13,15,65,66}$ In addition, compounds with inverted configuration at $\mathrm{C}-2^{\prime}$ and $\mathrm{C}-3^{\prime}(59,60$, and 61) were obtained by hydrolysis of the corresponding 2,2'-anhydronucleosides and 2,3'anhydronucleosides (e.g. $80 \rightarrow 61$ ). ${ }^{15}$

Substituted carbocyclic uracil nucleosides containing halogens at $C-5$ (56c-e, $57 \mathrm{c}-\mathrm{e}$ and $58 \mathrm{c}-\mathrm{e})$ were obtained by direct halogenation of the parent unsubstituted compound, ${ }^{66,67}$ including treatment with elemental fluorine to afford the interesting $5-\mathrm{F}-\mathrm{C}-\mathrm{dUrd}(57 \mathrm{c}) .{ }^{67}$ Other $\mathrm{C}-5$ substituents were introduced by displacement of the halogen (Br or I) with ammonia or various amines $(56 f, g ; 57 f-i ; 58 f, g)$. The 5-(hydroxymethyl)carbocyclic uracil 56h was obtained from the acetonide of C-Urd after treatment with paraformaldehyde. ${ }^{66}$

All carbocyclic uracil nucleosides with isosteric ring moieties of ribose, 2'deoxy, and $3^{\prime}$-deoxyribose $(56 a, 57 \mathbf{a}, 58 a)$ were inactive in culture against $\mathrm{KB}$ as well as L1210 cells. ${ }^{65}$ The very attractive 5-F-C-dUrd (57c), which is chemically stable and does not release 5-F-Ura, was anticipated to be more specific than 5-F-dUrd. However, it proved to be a rather weak and disappointing analogue of 5-F-dUrd that failed to increase the life span of mice bearing P388 and L1210 leukemias. This inactivity probably results from a low level of phosphorylation to the corresponding nucleotide. ${ }^{67} \mathrm{C}-$ Thy $(\mathbf{5 7 b})$ was the only member of the pyrimidine series with modest and reproducible activity against in vivo L1210 leukemia despite its inactivity against KB and H.Ep.-2 cells in culture. ${ }^{13}$

Like their pyrimidine nucleoside counterparts, many carbocyclic isosteres have shown good activity against HSV-1 and HSV-2 viruses (Table III). These carbocyclic analogues appear to be activated by viral-induced thymidine $\mathrm{ki}$ nase (TK) in view of their inactivity against TK $^{-}$variants. ${ }^{66}$ The carbocyclic analogue of I-dUrd was the most potent compound of the series.

\section{B. Cytosine Series}

The parent carbocyclic cytidine (C-Cyt, carbodine, 63a) was prepared from the $2^{\prime}, 3^{\prime}, 5^{\prime}$-tri-O-benzoyl carbocyclic uridine analogue via the intermediate 4chloro derivative after reaction with methanolic ammonia under pressure. ${ }^{69}$ Other $\mathrm{N}$-substituted analogues were obtained similarly by displacement of the chloride with the appropriate amine. ${ }^{68}$ The carbocylic analogues of $2^{\prime}$ deoxy and $3^{\prime}$-deoxycytidine (64a and 65a) were synthesized by the same procedure from the corresponding uracil derivatives (Table II). ${ }^{70}$ Both carbocyclic isosteres of cytosine arabinoside $(C$-ara- $C, 66)$ and the $3^{\prime}$-deoxyarabinosyl analogue 67, were obtained after hydrolysis of the corresponding 2,2'anhydrocytidine intermediates $(\mathbf{8 2} a, b)$ formed after treatment of carbocyclic cytidines $63 \mathbf{a}$ or $65 \mathbf{a}$ with DMF-thionyl chloride. ${ }^{70,71}$ 
Table III

Antiviral Activity of Selected Carbocyclic Pyrimidine Nucleosides

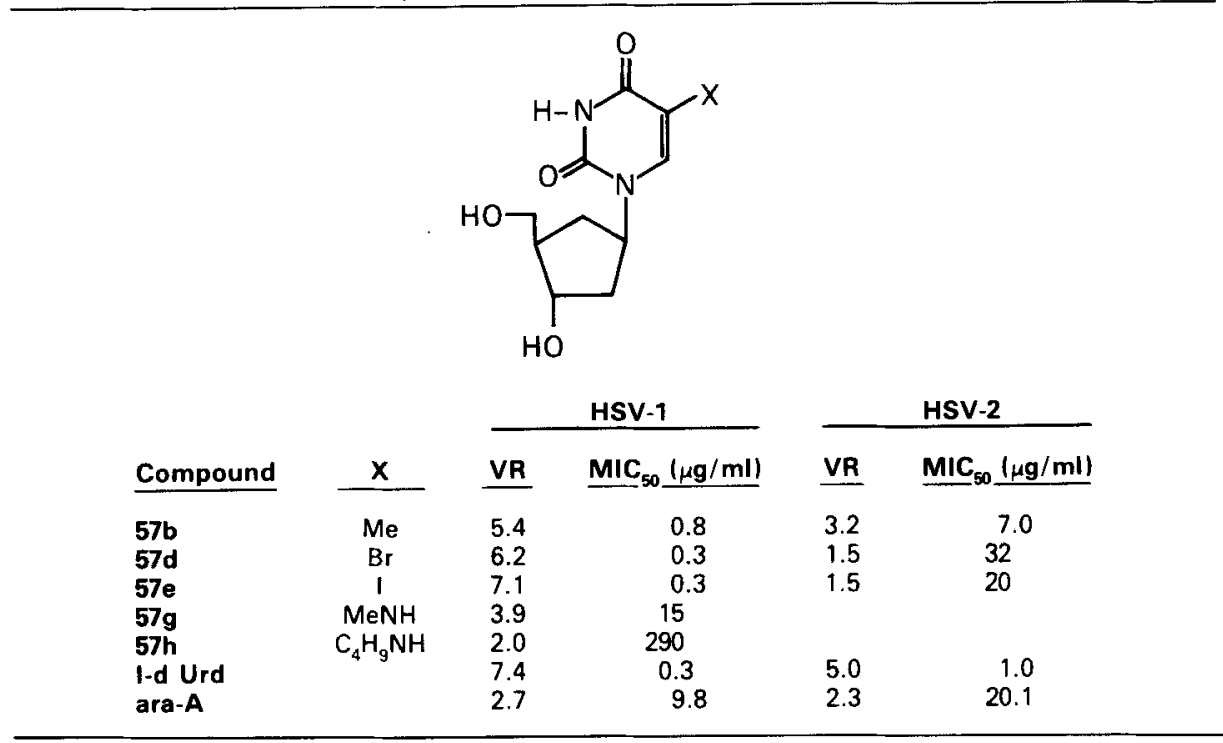<smiles>[X]C1C2C3Oc4nc(=N)ccn4C3C1(CO)C2[Y4]#[Y4]</smiles>

As antitumor agents, the carbocyclic cytidine analogues fared significantly better than their uridine counterparts as both C-Cyt and C-ara-C demonstrated good and reproducible activity against L1210 leukemia in mice. At $200 \mathrm{mg} / \mathrm{Kg}$ qd 1-9, C-Cyt gave $82 \%$ ILS, whereas C-ara-C at $150 \mathrm{mg} / \mathrm{Kg}$ produced $104 \%$ ILS. ${ }^{69-71} \mathrm{C}$-Cyt has been more thoroughly studied and it has been shown that L1210 cells phosphorylate it to the mono-, di- and triphosphate level and that it is subject to deamination by cytidine deaminase. 68,72 Accompanying the formation of C-CTP was a specific decrease in the CTP pool indicating inhibition of the critical step that converts UTP to CTP. ${ }^{68}$ This could be a limiting factor in the synthesis of RNA, but in vitro studies with L1210 cells revealed that DNA synthesis was inhibited to a greater extent than RNA synthesis. ${ }^{68}$ Since no significant incorporation into polynucleotides was observed, it is possible that C-CTP may interfere with DNA poymerase. ${ }^{68}$ As an antiviral agent C-Cyt was only marginally active against HSV-1; however, it showed good in vitro activity against influenza virus in mammalian cells. ${ }^{68}$ In vivo studies against this virus were negative, as well as the in vitro combination of C-Cyt with the cytidine deaminase inhibitor tetrahydrouridine. ${ }^{68}$ Both $2^{\prime}$ deoxy and $3^{\prime}$-deoxy isosteres (64a and 65a) were ineffective as either antitumor or antiviral agents. ${ }^{68,70}$ 


\section{CYCLOPENTENYL NUCLEOSIDES: THE NEPLANOCINS}

The neplanocin antibiotics comprise a group of compounds with variations in their carbocyclic moiety that depart significantly form the conventional carbocyclic nucleosides discussed thus far. Additionally, since they are the subject of much recent attention, they will be reviewed separately. The original members of the neplanocin family, which include neplanocin A-D, were isolated from a soil-derived strain of ampuriella regularis. ${ }^{73-75}$ The structure of neplanocin A (83) has been confirmed by spectral and X-ray analyses ${ }^{76,76 a, b}$ whereas the other neplanocins (84-87) have been briefly described. ${ }^{74,75,76 a}$

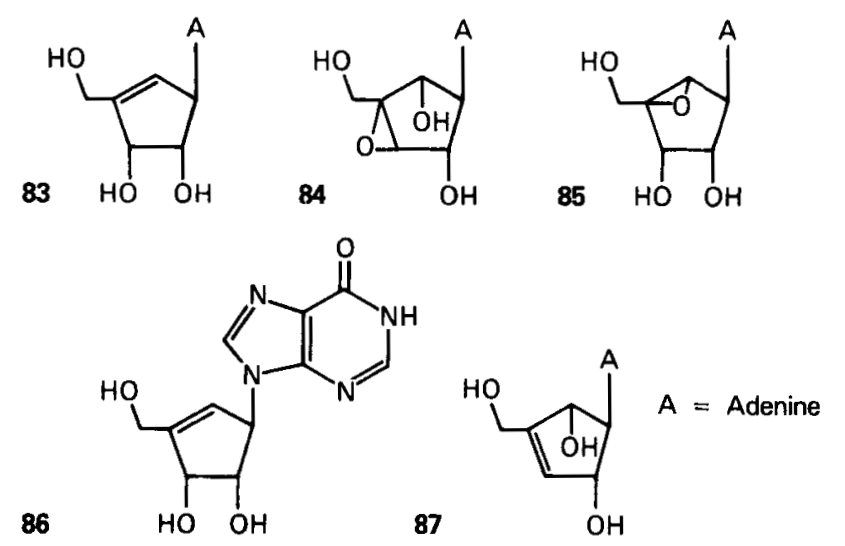

By far the most important member of the neplanocin family is neplanocin A which has demonstrated significant antitumor activity. ${ }^{75,76 a}$ Much of the published biological work refers to this compound as simply neplanocin. The neplanocin family has also been extended to other members including the pyrimidine analogues 88 and $89 .{ }^{77,86}$
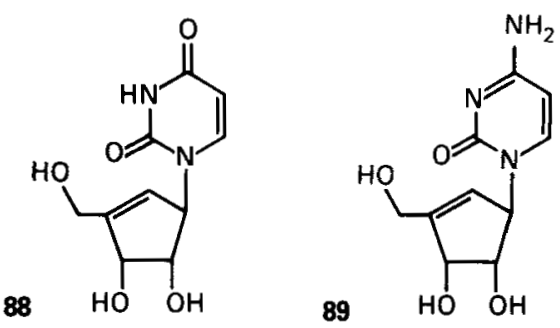

\section{A. Syntheses of Neplanocin}

The unprecedented presence of the double bond in the carbocyclic ring moiety of neplanocin expectedly attracted considerable synthetic attention. In 1983 three different total syntheses of neplanocin were reported which opened the route for the syntheses of other congeners. ${ }^{16-19}$ The highlights of these syntheses are briefly discussed.

The lactone intermediate 20 reported by Ohno in his synthesis of (-)aristeromycin (See Scheme IV) was reacted with PhSeNa to afford selenide 90. After a series of steps, which included a Curtius rearrangement and ad- 

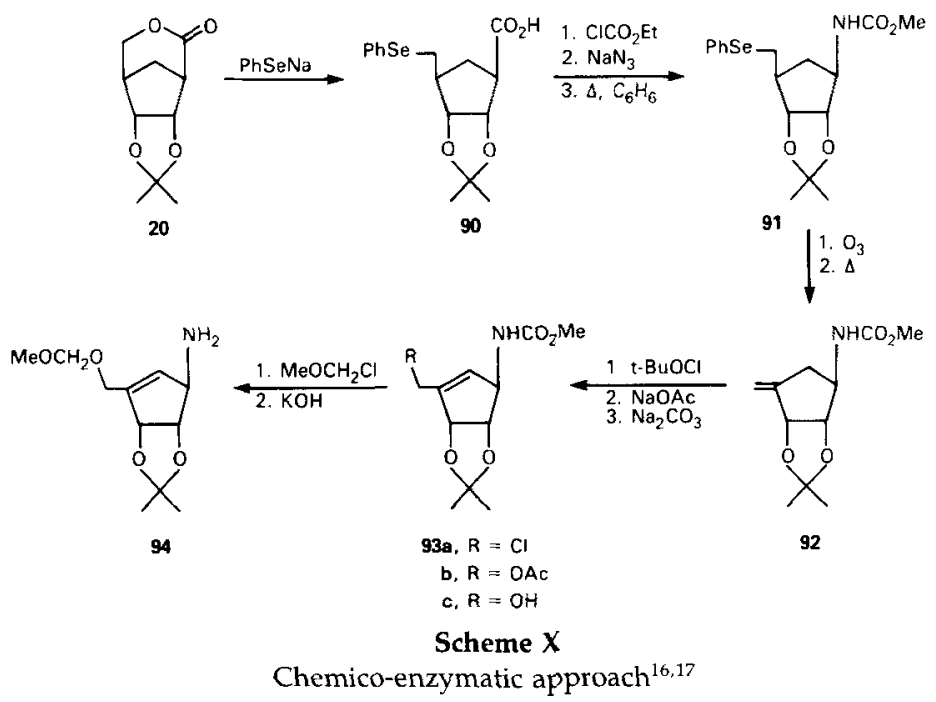

dition of methanol, the methyl carbamate 91 was obtained. Oxidation of 91 and syn elimination of the generated selenoxide afforded compound 92 which contained an exocyclic double bond. Transformation of 92 to the allylic alcohol 93c was performed in three steps involving an "ene-type" chlorination, displacement with acetate, and hydrolysis. Protection of the allyl hydroxyl in 93c as the methoxymethyl ether and hydrolysis of the carbamate, afforded the key amine 94 . This intermediate was used to prepare (-)-neplanocin, as well as the guanosine, AICAR, uridine, and cytidine analogues, through the use of conventional chemistry ${ }^{77}$ discussed earlier in this review.

In the chiron approach, use of chiral D- $(+)$-ribonic acid $\gamma$-lactone generated neplanocin in its naturally occuring enantiomeric form. Coupling the protected ribonolactone 95 with lithium dimethyl methylphosphonate, resulted in the formation of hemiketal 96. Benzoylation of 96 led to the dibenzoate 97 which afforded the acyclic ketophosphonate $\mathbf{9 8}$ after deprotection of the benzoyl groups. More conveniently, treatment of 96 with sodium methoxide afforded 98 directly. Oxidation of the alcohol function in 98 produced the 2,5diketophosphonate 99 which underwent a Wadsworth-Emmons cyclization to the cyclopentenone 100 . In the next step, the concave-convex nature of this bicyclo[3.3.0] system directed the hydride attack from the less congested $\beta$-face of the molecule to give the alcohol 101a. Mesylation of 101a, followed by $\mathrm{SN}_{2}$ displacement with $\mathrm{N}_{3}{ }^{-}$, afforded azide 102a which was subsequently reduced to the desired amine $\mathbf{1 0 2 b}$ having the $\beta$-configuration. This amine was further elaborated into (-)-neplanocin as well as into the corresponding uracil and cytosine carbocyclics. ${ }^{18,86}$

In the nitrone approach the masked amino group of the carbocyclic amine was incorporated in the starting material. ( \pm )-3-(3,5-Dinitrobenzoyl)-2-oxa-3azabicyclo[2.2.1]-hept-5-ene (103), which was easily available from a DielsAlder condensation of cyclopentadiene and the acylnitroso derivative of 3,5dinitrobenzoic acid, was subjected to a specific exo-cis dihydroxylation to the corresponding diol. Acetonide protection of this diol, followed by alkaline 


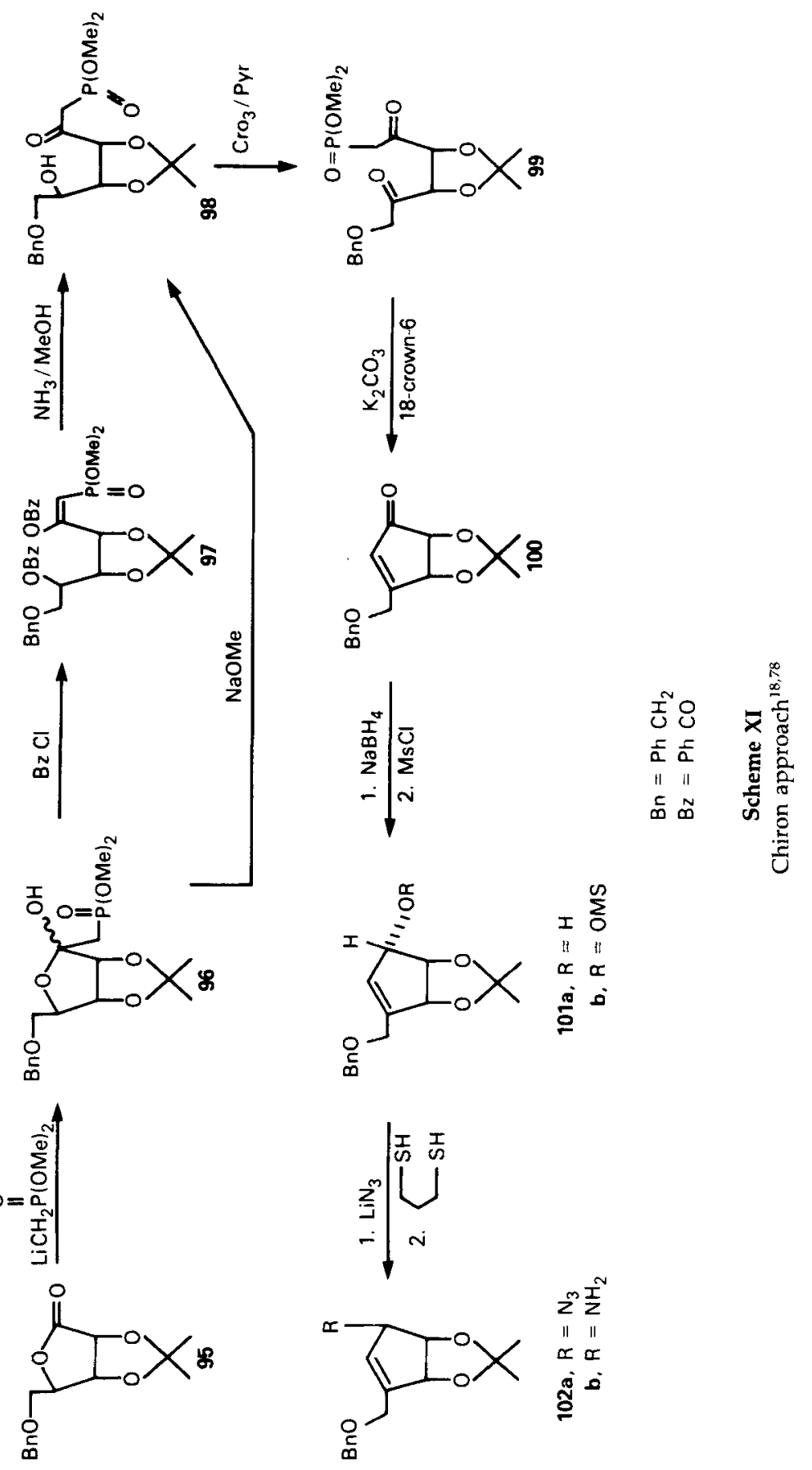




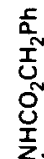
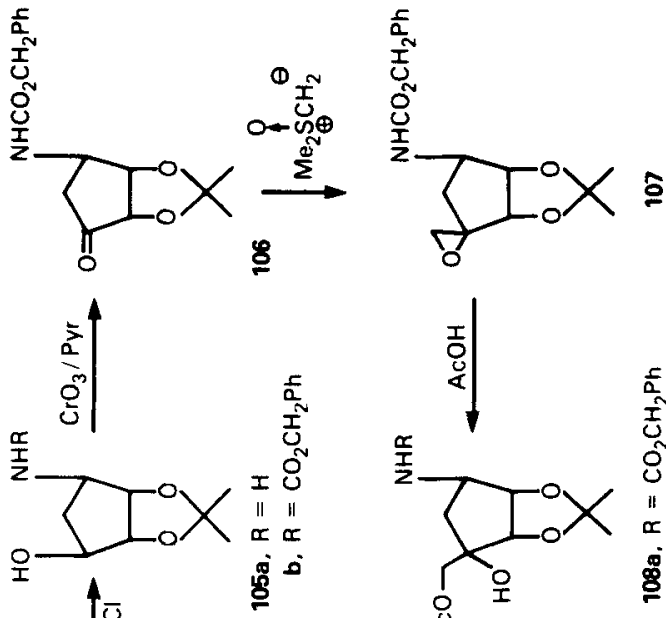

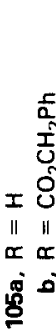

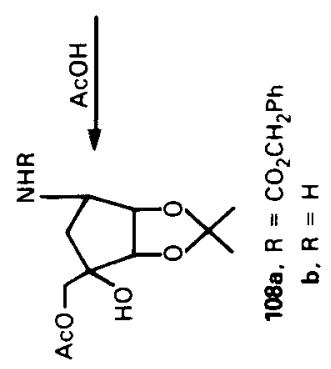

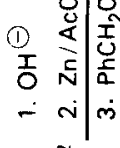
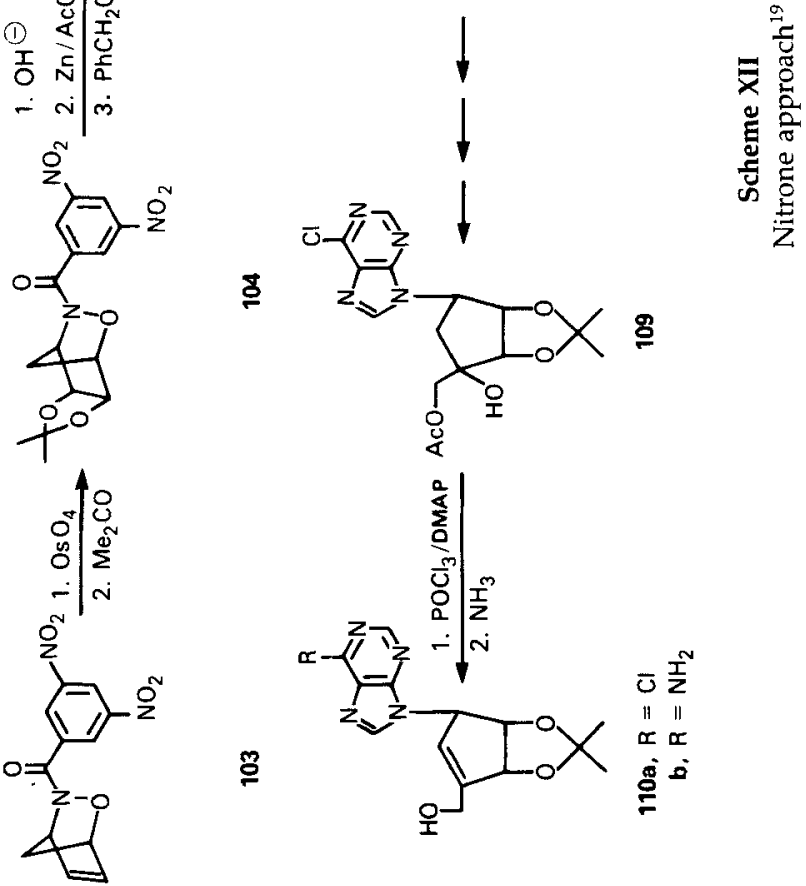
hydrolysis of the dinitrobenzamide and reductive cleavage of the N-O bond, afforded amine 105a. Protection of this amine and oxidation of the hydroxyl function resulted in the formation of cyclopentanone 106. Reaction of this cyclopentanone with the sulfurylide, dimethyloxosulfonium methylide, resulted in the regioselective formation of epoxide 107. Opening of the epoxide ring in glacial acetic acid, followed by deblocking of the amino protecting group, produced amine $\mathbf{1 0 8 b}$ upon which the purine ring was constructed. Dehydration of the tertiary alcohol in $\mathbf{1 0 9}$ afforded the desired carbocyclic skeleton and ammonolysis performed on the resulting product yielded the protected racemic neplanocin $\mathbf{1 1 0 b}$.

\section{B. Neplanocin Analogues}

Several purines and pyrimidines bearing the cyclopentenyl moiety have been prepared and many more are to be expected in the near future. Among the purine analogues that deserve special mention are a series of 2 '-modified carbocyclic isosteres represented by structure 111. Simultaneous protection the of $3^{\prime}$ and $5^{\prime}$-hydroxyls of neplanocin with Markiewickz's reagent (1,3dichloro-1,1,3,3-tetraisopropyldisiloxane) permitted the derivatization of the 2 '-hydroxyl into a leaving group that yielded compounds 111a-j after reaction with various nucleophiles. ${ }^{79,80,80 a} 2^{\prime}$-(R)-Mercapto-2'-deoxyneplanocin (111i) was characterized by $X$-ray analysis and the similarity of its $C D$ spectrum with those from other members of the series confirmed the structure of these analogues. ${ }^{81}$ The $2^{\prime}$-deoxy isostere was produced from the halogen-containing compounds $(111 \mathrm{a}-\mathrm{c})$, or from the corresponding $2^{\prime}$-O-thiocarbonylimidazoyl derivative, after reduction with tri-n-butyltin hydride. ${ }^{79} 3^{\prime}$-Deoxy neplanocin, the analogue of cordycepin, was obtained by a similar procedure. ${ }^{80 a}$

Other modified neplanocins including the 5 '-amino and $5^{\prime}$-azido-5'-deoxyneplanocins have been reported in several patents. ${ }^{82-84}$

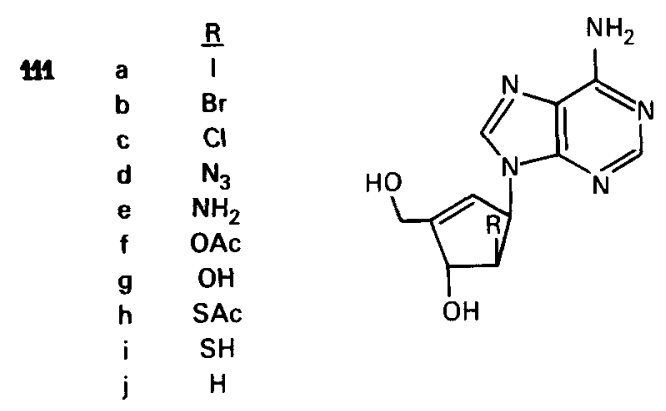

\section{Biological Activity}

\section{a. Purine Analogues}

Neplanocin A was reported to have a striking effect in increasing the life span of mice bearing L1210 leukemia (ILS $120 \%$ at $5 \mathrm{mg} / \mathrm{Kg}$, qd 1-5) with a rather broad margin of safety. ${ }^{75,76 a}$ It was nevertheless deaminated to the inactive inosine isostere (neplanocin $D, 86$ ), but with a $V_{\max } 60$-fold lower than adenosine. ${ }^{75}$ At the National Cancer Institute neplanocin demonstrated somewhat less pronounced activity against both L1210 (ILS $62 \%$ at $4 \mathrm{mg} / \mathrm{Kg}$ ) 
and P388 (ILS 53\% at $4 \mathrm{mg} / \mathrm{Kg}$ ) leukemias. In addition, it was inactive against a host of other tumors including xenografts. ${ }^{85}$

\section{b. Pyrimidine Analogues}

The only compounds reported thus far in this series are the uridine and cytidine isosteres 88 and 89 . Their in vitro study with KB and L1210 cells revealed that only the cytidine analogue was cytotoxic. ${ }^{77,86} \mathrm{The}^{\mathrm{IC}} \mathrm{C}_{50}$ for this compound against L1210 was $30 \mathrm{nM}$, while the uridine analogue inhibited cell growth only $12 \%$ and $36 \%$ at $0.5 \mathrm{mM}$ and $1 \mathrm{mM}$, respectively. ${ }^{86}$ Both compounds, however, behaved as competitive inhibitors of uridine kinase with $K_{i}$ values of $60 \mu \mathrm{M}$ (cytidine analogue 89) and $230 \mu \mathrm{M}$ (uridine analogue 88) and likewise capable of selectively inhibiting uridine and cytidine salvage in intact cells. ${ }^{86}$ When compared with the saturated carbocyclic isosteres 56a $\left(K_{i}=930 \mu \mathrm{M}\right)$ and $63 \mathrm{a}\left(\mathrm{K}_{\mathrm{i}}=250 \mu \mathrm{M}\right)$ the level of kinase inhibition was superior for the unsaturated analogues by a factor of $4 .{ }^{87}$ The cytotoxicity associated with the cytidine isostere appears to be related to potent inhibition of CTP synthesis which occurred at doses tenfold lower than with carbodine (C-Cyt, 63a) in HT-29 human colon carcinoma cells. ${ }^{88,89}$ In addition, drug exposure for $24 \mathrm{~h}$ with this compound completely inhibited DNA synthesis in these cells at concentrations of the drug ca. $0.25 \mathrm{uM}^{88}$

Some recent unpublished observations appear to indicate that this compound is also a powerful differentiator of HL-60 cells, producing even a greater effect than retinoic acid. ${ }^{90}$

\section{CARBOCYCLIC ANALOGUES OF C-NUCLEOSIDES}

Since the isolation of pseudouridine (112) a new class of nucleosides was discovered in which the characteristic $\mathrm{C}-\mathrm{N}$ linkage between sugar and base was replaced by a $\mathrm{C}-\mathrm{C}$ bond. These carbon nucleosides, or $\mathrm{C}$-nucleosides, such as formycin, formycin B, showdomycin, pyrazofurin, and oxazinomycin, possess antibiotic properties and many exhibited antiviral or anticancer activities. ${ }^{91}$ The chemistry and biological properties of $C$-nucleosides have been described in several reviews. ${ }^{92-95}$<smiles>O=c1[nH]cc(C2OC3C(O)C2C3O)c(=O)[nH]1</smiles><smiles>O=c1[nH]cc(C2CCC(P)C2)c(=O)[nH]1</smiles><smiles>O=c1[nH]cc(C2CCC(O)C2)c(=O)[nH]1</smiles>
112

$\begin{aligned} \text { 113a. } R & =\stackrel{H}{\text { b. }} \mathrm{R}=\stackrel{\mathrm{OH}}{\mathrm{O}}\end{aligned}$ 114

A logical extension in the quest for new synthetic bioactive molecules was to incorporate the carbocyclic moiety into this class of compounds. As early as 1966, some carbocyclic 5-monohydroxycyclopentylpyrimidines (113a) and 5-dihydroxycyclopentylpyrimidines (113b), which bear a structural similarity to pseudouridine, were prepared. ${ }^{96,97}$ These compounds together with the 


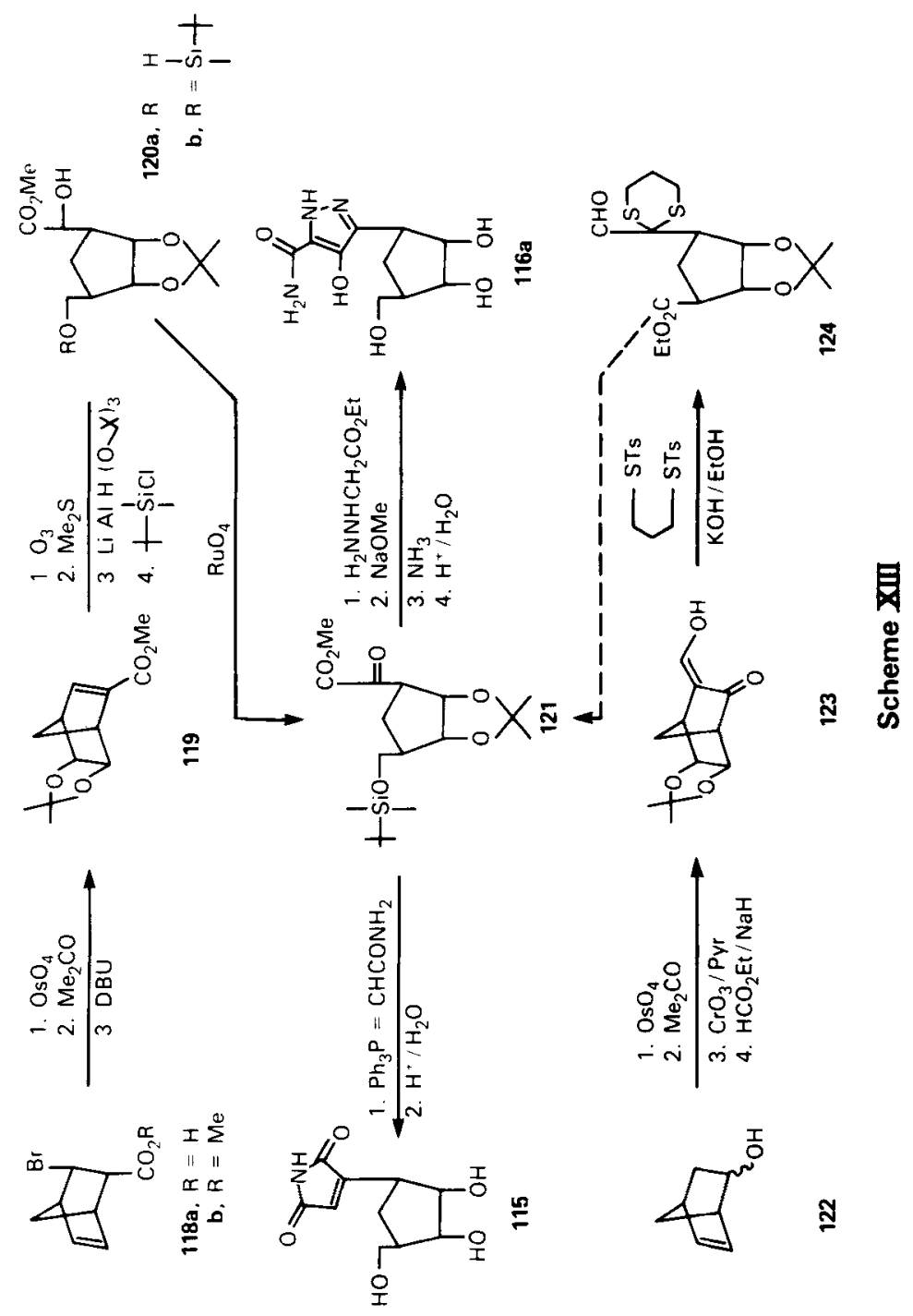


carbocyclic analogue of 2', 3'-dideoxypseudouridine 114 were used as probes to study the intramolecular $\mathrm{H}$-bonding capacity of pseudouridine. ${ }^{98} \mathrm{~A}$ more systematic approach to carbocyclic C-nucleosides was begun by Just and coworkers who prepared carbocyclic isosteres of DL-showdomycin (115), ${ }^{99} \mathrm{DL}$ pyrazofurin (116a), ${ }^{99,100}$ 2'-deoxy-DL-pyrazofurin (116b), ${ }^{101}$ DL-6-azapseudouridine (117), ${ }^{100}$ 2-thio-6-azapseudouridine ${ }^{100}$ and several others. ${ }^{102,103}$ In a manner reminiscent of Shealy's approach, the Diels-Alder adduct 118a, obtained from cyclopentadiene and bromoacrylic acid, was used as the starting point (Scheme XIII). ${ }^{104,105}$ Following cis hydroxylation of the corresponding ester 118b with $\mathrm{OsO}_{4}$, the resulting exo diol was protected as the isopropylidene derivative, and after base catalyzed elimination of $\mathrm{HBr}$, the olefin ester 119 was obtained. Ozonolysis, followed by reduction with dimethyl sulfide gave the corresponding ketoaldehyde which was further reduced to the diol $120 \mathrm{a}$. Selective protection of the primary alcohol to give $120 \mathrm{~b}$ and oxidation of the secondary alcohol, afforded the key $\alpha$-ketoester 121 . This $\alpha$-ketoester was used in the synthesis of the carbocyclic isosteres of showdomycin (115) and pyrazofurin (116a). ${ }^{99,101}$ Independently, Saksena arrived at the critical precursor to intermediate $\mathbf{1 2 1}$ by a different route as shown in Scheme XIII. ${ }^{106}$ Continued interest in the synthesis of these structurally interesting compounds was reduced by the lack of biological activity displayed by the first prototypes in preliminary studies. ${ }^{99}$
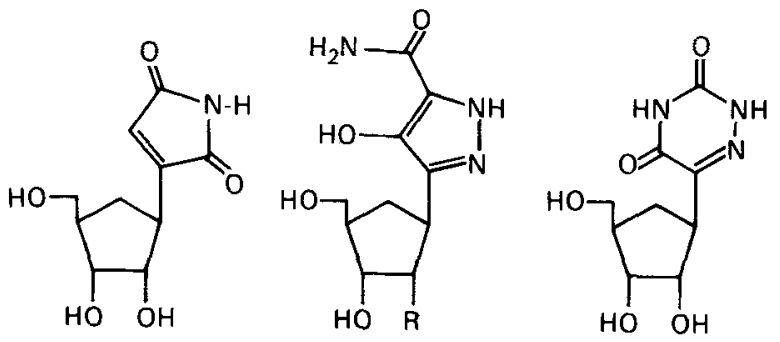

115

116a, $R=\mathrm{OH}$

b, $R=H$

117

\section{MISCELLANEOUS}

The term carbocyclic nucleoside can also be extended to include a series of compounds with altered carbocyclic moieties that significantly separate them from the rest of the other carbocyclic ribose isosteres in that they lack the hydroxymethyl group that permits formation of the corresponding nucleotide analogue. For this reason they will be reviewed separately, and not as extensively, except in some important cases where the lack of such functionality proved to be biologically advantageous. A case in point was the puromycin analogue 125a which displayed antimicrobial activity virtually identical to that of puromycin but with the advantage that after metabolic removal of the amino acid moiety, the released aminonucleoside was resistant to kinase activity and unable to generate the nephrotoxic aminonucleotide which was otherwise generated from puromycin. ${ }^{107}$ Two syntheses have been reported for this compound (Scheme XIV) both of which produced the racemate. ${ }^{107,108}$ In one of the approaches, however, compound $135 \mathrm{~b}$ was resolved and the 


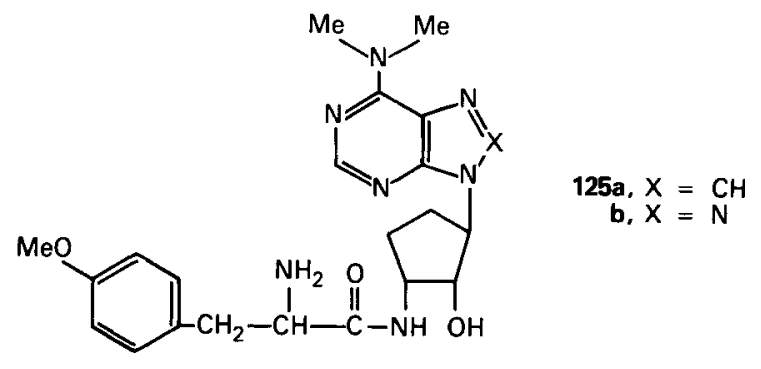

two diastereoisomeric carbocyclic puromycin analogues were obtained. ${ }^{108}$ The syntheses were straightforward with some of the highlights being the direct conversion of the ketal 130 to oxime 131 by $\mathrm{NH}_{2} \mathrm{OH} . \mathrm{HCl}(\mathrm{pH} \mathrm{1})$, and the highly stereospecific diborane reduction of $\mathbf{1 3 1}$ to the carbocyclic aminonucleoside 132 (isolated as the acetate). ${ }^{107}$ In the most recent approach, the cis directing effect of the allylic amido group in $\mathbf{1 3 3}$ proved to be the driving force to direct formation of the required epoxide $134 .{ }^{108}$ Completion of the purine ring in both approaches was performed by the standard methodology.

In regard to their mechanism of action, only the diastereoisomer analogous to puromycin was shown capable of accepting the acetylalanine residue from acetylphenylalanyl-RNA. ${ }^{109}$ Furthermore, in addition to the expected antimicrobial activity, the compound was active against three tumor lines in tissue culture. ${ }^{110}$ Later, by a similar strategy, the 8 -aza analogue $125 \mathrm{~b}$ was prepared and found to act in a manner similar to puromycin. ${ }^{111}$

Suami et al. subsequently altered the carbocyclic moiety of 125a replacing it with isomers of 3-amino-2,4,5-trihydroxycyclopentane. Eight diastereoisomeric carbocyclic puromycin analogues were prepared but only two (136 and 137) showed activity against HeLa cells in tissue culture. ${ }^{112}$

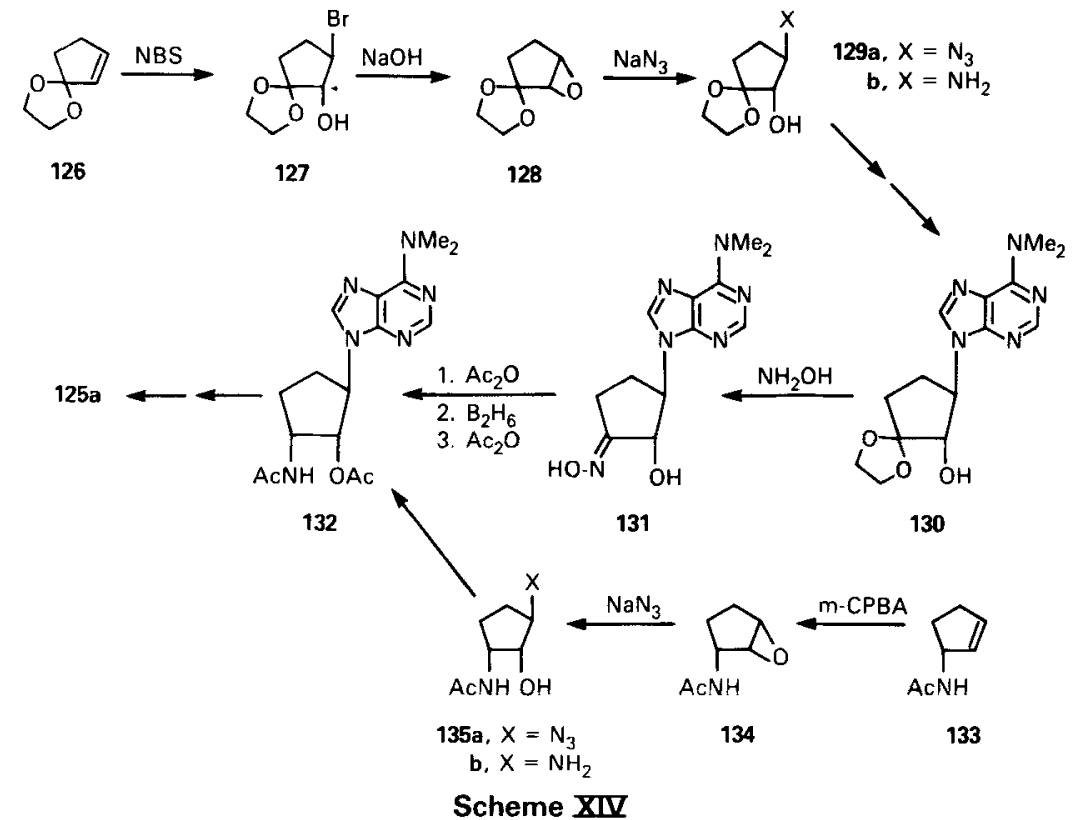



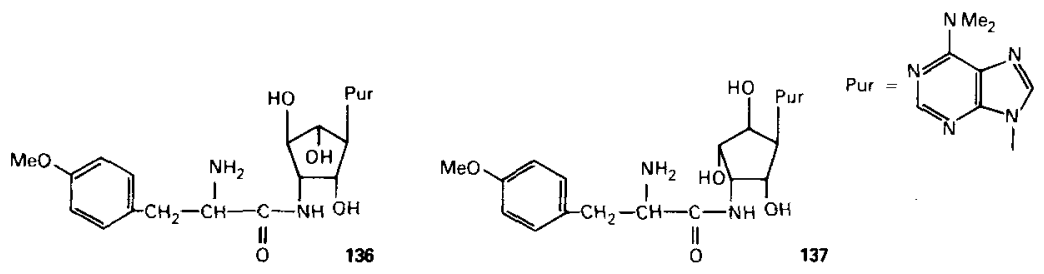

In other reports, analogues of $9-\left(2^{\prime}, 3^{\prime}, 4^{\prime}, 5^{\prime}\right.$-tetrahydroxycyclopentyl $)$ adenines (138), derived form five of the ten possible isomers of 5 -aminocyclopentanetetrol, were prepared and shown to have some antifungal activity. ${ }^{113}$ Similarly, the synthesis of analogous 3'-amino-3'-deoxy derivatives (139) was accomplished but the compounds were devoid of activity against HeLa cells. ${ }^{114}$

138

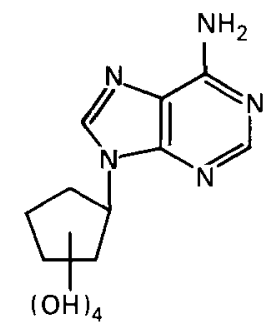

139<smiles>Nc1ncnc2c1ncn2C1CCC(N)C1</smiles>

Several more carbocyclic analogues of adenosine and pyrimidine nucleosides in which the ribofuranosyl moiety was replaced by polyhydroxycyclopentyl or polyhydroxycyclohexyl groups have been prepared, but as might be expected, their biological activity was of no significance. ${ }^{11,115-117}$

\section{CARBOCYCLIC NUCLEOSIDES AND ENZYMATIC METHYLATION REACTIONS}

In view of the very specific inhibition of enzymatic methylation reactions brought about by a group of carbocyclic nucleosides, the aspects concerning this activity will be discussed separately.

\section{A. Background}

Very important biological methylation reactions are catalyzed by S-adenosylmethionine (AdoMet)-dependent methyl transferases in which transfer of the methyl group occurs via nucleophilic displacement by electron-rich groups $(\mathrm{OH}, \mathrm{NH}, \mathrm{SH}$ or double bonds) present in the methyl acceptor molecule (Figure 2). The methyl acceptor moieties can be small molecules (i.e. triptamine, histamine), medium-size molecules (i.e. phospholipids), or macromolecules (i.e. RNA, DNA, and proteins). ${ }^{118,118 a, 120}$

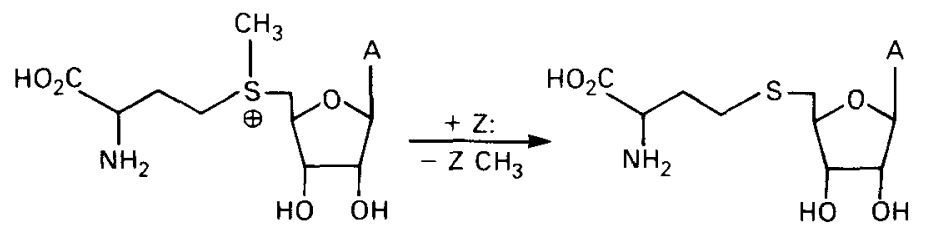




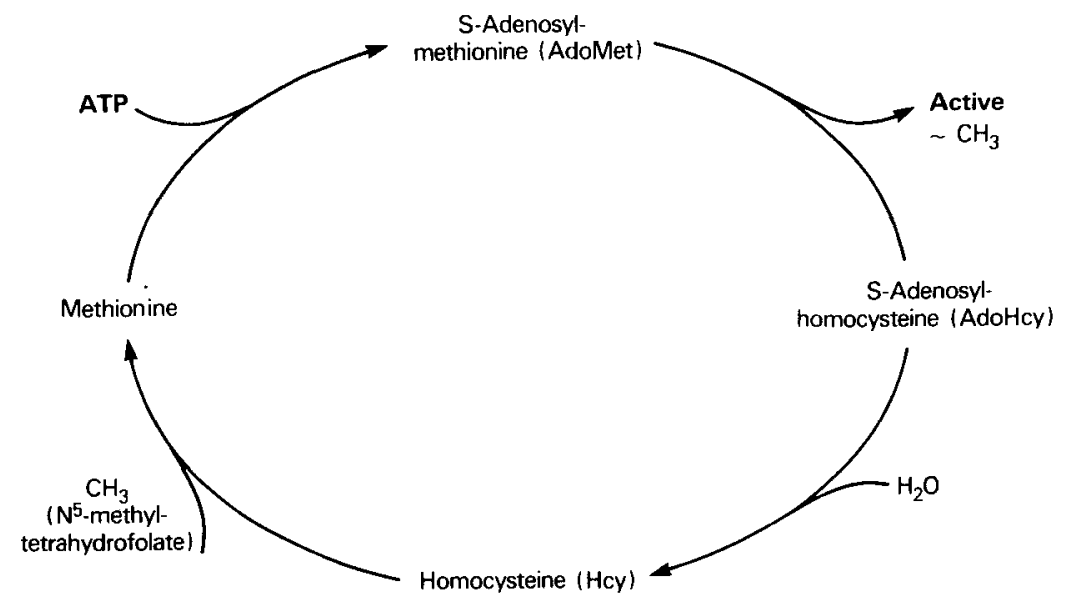

Figure 2. Activated Methyl Cycle.

After methyl transfer, the resulting product from AdoMet (140) is adenosylhomocysteine (AdoHcy, 141) which in turn behaves as a very powerful feedback inhibitor of the methylation reaction. ${ }^{119}$ Therefore, another enzyme (AdoHcy hydrolase or AdoHcy-ase) efficiently removes this material by cleaving it to adenosine (Ado) and homocysteine (Hcy). Kinetically, however, AdoHcy hydrolysis is a reversible reaction favoring the synthesis of AdoHcy, but its direction is nevertheless forced in the hydrolytic sense due to the efficient removal of Ado and Hcy by further metabolism (i.e. deamination or phosphorylation of Ado and remethylation of Hcy back to methionine). ${ }^{120}$ Inhibition of AdoHcy-ase will therefore result in increased levels of AdoHcy and consequent inhibition of methylation. ${ }^{121}$ Furthermore, since cells cannot eliminate AdoHcy across the membrane, the effects of inhibition of methylation are expected to be relatively long lasting. ${ }^{122}$ Inhibition of methyltransferases via alteration of the AdoHcy metabolism has attracted considerable attention as a target for drug design particularly in relation to the inhibition of a critical methylation reaction necessary for the proper processing of viral messenger RNA. ${ }^{123-125}$ These mRNA molecules must be capped and methylated at their $5^{\prime}$-terminus in order to initiate translation into viral proteins. ${ }^{126}$ Not surprisingly, therefore, many potent inhibitors of AdoHcy-ase have shown good antiviral activity against viruses requiring a methylated 5'-cap mRNA. ${ }^{48,121,125,127}$ Also, the biochemical connection between methylation patterns in macromolecules, particularly in RNA and DNA, in tumors as well as in cells transformed by oncogenic viruses, has heightened the importance of AdoHcy-ase as a target for chemotherapeutic agents. ${ }^{128,129,129 a} \mathrm{~A}$ matter of concern, however, is the possible lack of specificity resulting from an indiscriminate inhibition of other methylases due to the increased levels of AdoHcy. ${ }^{118,130}$

\section{B. Mechanism of Adenosylhomocysteine Hydrolase (AdoHcy-ase)}

The mechanism of AdoHcy-ase was elegantly elucidated by Abeles and Palmer who demonstrated that the reaction proceeds with the temporary oxidation of the C-3' hydroxyl of the substrate in either direction (AdoHcy or Ado) through the action of enzyme-bound NAD (Figure 3). ${ }^{131,132}$ This 


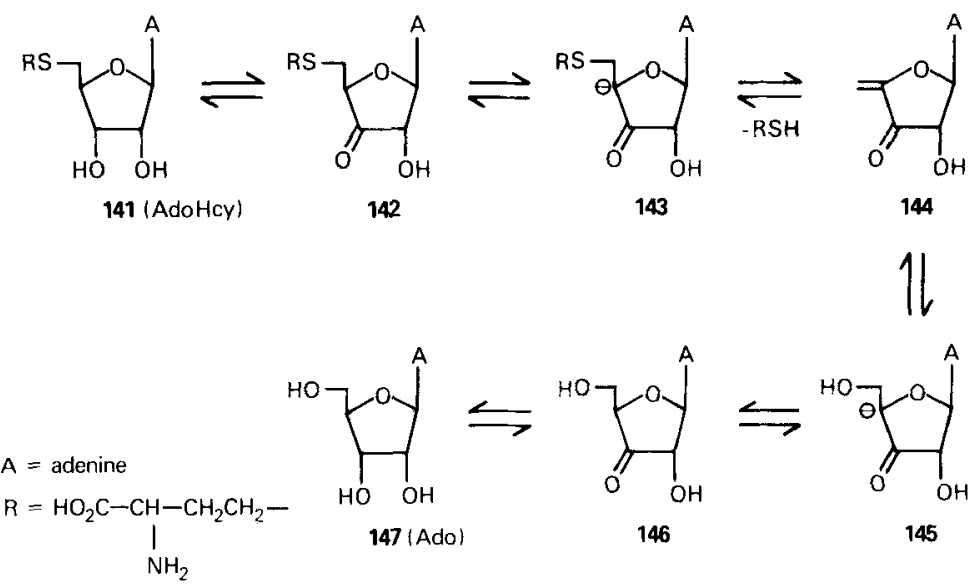

Figure 3. Mechanism of AdoHcy-ase.

oxidation facilitates the elimination of Hcy from AdoHcy, or the hydroxyl group from Ado, after a base-catalyzed removal of the C-4' proton to give a $3^{\prime}$-keto-4',5'-dehydroadenosine intermediate 144. A Michael-type addition on this intermediate ensues by either water or Hcy, followed by the subsequent reduction back to the ribose moiety mediated by NADH. By this strategy the enzyme converts a difficult displacement reaction into a more facile elimination-and-addition reaction. The $\mathrm{K}_{\mathrm{m}}$ 's for AdoHcy and Ado are, respectively, $10.5 \mu \mathrm{M}$ and $45 \mu \mathrm{M}$ for the beef liver enzyme. ${ }^{132}$

\section{AdoHcy-ase Inhibitors}

An important number of purine nucleosides, analogous to adenosine, interfere with AdoHcy-ase resulting in various degrees of inhibition of AdoMetmediated methylation reactions. ${ }^{133-136}$ This phenomenon is thought to be the direct consequence of increased levels of AdoHcy which change the critical AdoMet/AdoHcy ratio. ${ }^{118}$ Many of these nucleosides also serve as substrates for AdoHcy-ase, thus, generating novel S-nucleosidylhomocysteine analogues (NucHcy's) from the purine nucleosides and Hcy. ${ }^{133-135}$ However, it appears for the most part that the elevation of AdoHcy levels and not the novel metabolites are chiefly responsible for the inhibition of methylations. The inhibition of AdoHcy-ase occurs by a nucleoside dependent mechanism. For example, some of the ribose-modified Ado analogues, such as Ara- $A$ and 2 '-dAdo, inhibit the enzyme irreversibly (suicide inhibitors) and do not serve as substrates for the enzyme, ${ }^{133-137}$ Others function as potent reversible inhibitors, as well as substrates, as is the case of the base-modified analogue 3 -deazaadenosine (3-deaza-Ado), ${ }^{135}$ while some purine nucleosides function strictly as substrates without causing any elevation of AdoHcy levels (e.g. nebularine). ${ }^{133,134}$ In a few instances some nucleosides form the NucHcy analogue independently of AdoHcy-ase possibly as a result of transmethylation reactions that use the NucMet analogue as a methyl donor. This NucMet metabolite could be formed from the reaction between the nucleoside triphosphate (substituting for ATP) and methionine. ${ }^{133}$ 
Table IV.

Summary of the Biochemical Properties of Purine Nucleoside and Carbocyclic Nucleoside Inhibitors of AdoHcy-ase.

\begin{tabular}{|c|c|c|c|c|c|c|c|}
\hline Compound & $\frac{\text { AdoHcy-ase }}{\text { substrate }}$ & $\frac{\text { AdoHcy-ase }}{\left(K_{i}\right)}$ & $\begin{array}{l}\text { Type of } \\
\text { Inhibition }\end{array}$ & $\frac{\text { NucMet }}{\text { formed }}$ & $\frac{\text { NucHcy }}{\text { formed }}$ & $\frac{\text { Kinase substrate }}{\text { (AK) }}$ & $\frac{\text { ADA }}{\text { substrate }}$ \\
\hline Adenosine & + & $K_{m}=45 \mu M^{132}$ & & + & + & + & + \\
\hline $2^{\prime}$-Deoxyadenosine & - & $1260 \mu M^{136}$ & irreversible & - & - & + & + \\
\hline ara-Adenosine & - & $300 \mu M^{136}$ & irreversible & - & - & + & + \\
\hline 3-Deazaadenosine & + & $\begin{array}{c}4 \mu M^{135} \\
20 \mu M^{136} \\
1 \mu M^{135}\end{array}$ & reversible & - & + & - & - \\
\hline C-Ado (35a) & - & $\begin{array}{l}0.005 \mu M^{135} \\
0.051 \mu M^{136}\end{array}$ & irreversible & + & - & + & + \\
\hline 3-Deaza-C-Ado (50a) & - & $\begin{array}{c}3 \mu M^{48} \\
0.001 \mu M^{48}\end{array}$ & reversible & - & - & - & - \\
\hline Neplanocin (83) & - & $\begin{array}{l}0.008 \mu M^{138} \\
0.021 \mu M^{136}\end{array}$ & irreversible & + & - & + & + \\
\hline
\end{tabular}

A dramatic change in substrate, binding properties, and mode of inhibition, takes place among some of these nucleosides when the sugar moiety is replaced by a carbocyclic ring. As seen in Table IV the $K_{i}$ values are often 100 to 1000 times lower. C-Ado is one of the nucleosides with the lowest activity as a substrate for AdoHcy-ase, but in contrast, is one of the most potent inhibitors of the enzyme. ${ }^{135}$ Another carbocyclic nucleoside analogue is 3deaza-C-Ado (50a), which like its riboside isostere 3-deazaadenosine, is resistant to both adenosine deaminase (ADA) and adenosine kinase (AK) besides serving as a poor substrate for AdoHcy-ase. ${ }^{48}$ Although its $K_{i}$ is not as impressive, the compound appears to be more specific and superior to $\mathrm{C}$ Ado in intact cells. ${ }^{134 a}$ It does not inactivate the enzyme and conversion to the NucHcy metabolite does not readily take place. ${ }^{48}$ The antiviral activity of 3-deaza-C-Ado which probably results from the increased levels of AdoHcy and consequent inhibition of methylation of the $5^{\prime}$-cap of viruses, was discussed previously (Section III-C). ${ }^{48,127}$ The chemical syntheses of NucHcy metabolites of C-Ado and 3-deaza-C-Ado have been reported. ${ }^{48,135 a, b}$ Of particular interest was the finding that the aristeromycinyl homocysteine analogue of AdoHcy was a potent inhibitor of several methyltransferases displaying different degrees of selectivity towards each enzyme. ${ }^{135 b}$ The synthesis of the NucHcy analogue of 43d containing a plain cyclopentyl ring was also reported. ${ }^{135 c}$ The additional presence of the double bond in the carbocyclic structure represented by neplanocin, produced even further changes in activity. The inhibitory activity against AdoHcy-ase was comparable to that of C-Ado $\left(\mathrm{K}_{\mathrm{i}}=0.0089 \mu \mathrm{M}\right)$ and appeared to be consistent with irreversible inhibition (tight binding) of the enzyme. ${ }^{136,138}$ Like C-Ado, neplanocin is deaminated and phosphorylated to the triphosphate level; however, some important differences exist between these two compounds. First and foremost, CAdo, although cytotoxic to H.Ep.-2 and L1210 cells in vitro, is completely devoid of in vivo antitumor activity. ${ }^{10}$ Neplanocin, on the contrary, possessed significant antitumor activity in vivo against murine leukemias. ${ }^{75}$ Also, as expected for an inhibitor of AdoHcy-ase, neplanocin displayed potent antiviral activity against vaccinia virus in mouse L-929 cells with little or no toxicity to 
the host cell. ${ }^{138}$ Consistent with its potent inhibitory activity against AdoHcyase, neplanocin produced a dramatic inhibition of the hydrolase in infected L-cell cultures resulting in a 10-fold increase in the intracellular AdoHcy/AdoMet ratio after a $24 \mathrm{~h}$ exposure of $1 \mu \mathrm{M}$ of drug. ${ }^{138}$ Neplanocin is phosphorylated but does not appear to be incorporated into RNA or DNA as was the case with C-Ado. ${ }^{139}$ It was, however, highly toxic to Chinese hamster ovary cells $(\mathrm{MIC}=0.1 \mu \mathrm{M})$ and cytotoxicity to cells lacking the kinase remained almost unchanged $(\mathrm{MIC}=0.5 \mu \mathrm{M}) .{ }^{140}$ Despite the fact that neplanocin is deaminated by ADA to its inactive inosine analogue, addition of ADA inhibitors did not enhance its toxicity. ${ }^{138-140}$ On the other hand, neplanocin was not highly cytocidal to HT-29 cells when compared to other adenosine analogues and its principal effect was inhibition of RNA methylation. ${ }^{139}$ As with C-Ado, it was not a good substrate for AdoHcy-ase and consequently the NucHcy analogue was not apparently formed. ${ }^{139}$ This NucHcy metabolite was nevertheless detected as a consequence of a transmethylation reaction that used the NucMet analogue as a methyl donor species. ${ }^{139-141}$ In fact, this NucMet metabolite appeared to be the principal metabolite in both HT-29 cells as well as in mouse L-929 cells. ${ }^{139,141}$ This would indicate that the NucMet anabolite can interfere at yet another level of the methylation reaction by directly competing with AdoMet, or blocking it after irreversibly binding to the enzyme.

Inhibition of AdoMet decarboxylase, such as demonstrated for 3-deazaAdo, 3-deaza-C-Ado and their NucHcy conjugates, could also play a role in the effects of these carbocyclic analogues by affecting polyamine metabolism. ${ }^{141 a}$ The activity of neplanocin in this area remains to be studied.

\section{Mechanism of Action of AdoHcy-ase Inhibitors.}

In light of the mechanism discovered by Abeles ${ }^{131,132}$ it could be proposed that the inhibitors may (a) compete in a reversible manner with Ado without being essentially transformed by the enzyme (e.g. 3-deaza-C-Ado ${ }^{48}$ ); (b) compete in a reversible manner with Ado but simultaneously converted by the enzyme to the NucHcy analogue (e.g. 3-deaza-Ado ${ }^{134}$ ); or (c) compete with Ado and irreversibly inhibit the enzyme by causing it to catalyze its own inactivation (e.g. neplanocin, ${ }^{138}, 2^{\prime}-\mathrm{d}-\mathrm{Ado}^{137}$ ). From a mechanistic stand-point, this last group is the most interesting one particularly since most carbocyclic analogues appear to inhibit the enzyme in this suicidal manner. The suicide inactivation of AdoHcy-ase by $2^{\prime}$-dAdo results from the inherent chemical instability of the enzyme-generated $3^{\prime}$-ketonucleoside $148 .{ }^{137}$ This intermediate can undergo a favorable trans-elimination to give adenine and a sugar residue (149). As a result of this elimination, the enzyme is left with its unreacted cofactor (NADH), and hence, it is unable to initiate another cycle

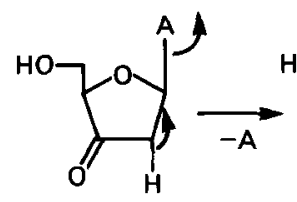

148

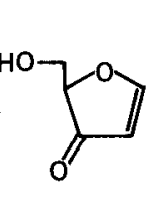

149
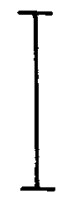

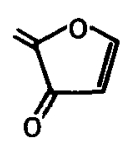

151 
of catalysis due to the fact that its tightly bound NADH cannot be replaced by exogenous NAD. ${ }^{137}$ Despite the apparent reactivity of the resulting sugar residue formed (149), there appears to be no covalent modification of the enzyme. ${ }^{137}$ On a closer analysis, however, this $\alpha, \beta$-unsaturated system may in fact be chemically deactivated by the furanose oxygen. Nevertheless, according to Abeles, there is also an additional loss of adenine that does not require NAD oxidation and simply results from cleavage of the glycosidic bond. Therefore, an interesting alternative would be the loss of adenine at the next stage of the enzymatic reaction from 150 (formed as depicted in Figure 3 for adenosine) which would lead to the very reactive intermediate 151. This very intermediate has been suggested as the metabolite responsible for the irreversible inactivation of ribonucleoside diphosphate reductase (CDP and ADP reductase) induced by $2^{\prime}-F-2^{\prime}$-deoxynucleosides which generate 151 through a different mechanism. ${ }^{142,143}$

In the case of the carbocyclic analogues, C-Ado and NPC-A, which also inactivate the enzyme in an irreversible manner, there are some mechanistic similarities. ${ }^{135,144}$ For example, addition of either C-Ado or neplanocin leads to an irreversible reduction of enzyme-bound NAD and hence both compounds generate a catalytically incompetent form of the enzyme (NADH form). Also, there appears to be elimination of adenine from 152 or 154 which has to proceed either via a cis-elimination or a trans-elimination (the latter occurring after isomerization of the $\alpha$-keto hydroxyl group through its enol form).

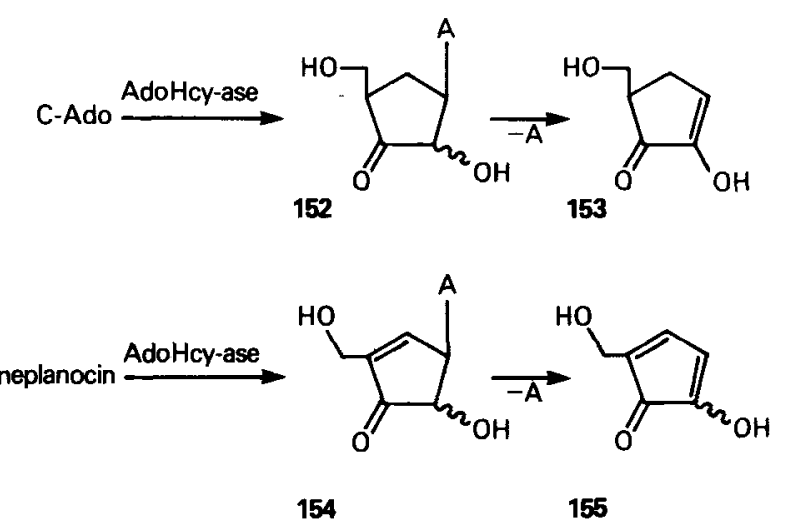

In the case of $\mathrm{C}$-Ado, the generated $\alpha, \beta$-unsaturated ketone is also a poor Michael acceptor because the $\alpha-\mathrm{OH}$ deactivates the double bond. However, if adenine elimination (cis or trans) were to take place after the next step of the enzymatic reaction from 156, it would generate a more reactive species (157) capable of binding covalently to the enzyme. The difference in reactivity between 151 and 157 could explain the $10^{5}$-fold difference between $2^{\prime}$-d-Ado and C-Ado. ${ }^{135,137}$

In the case of neplanocin, a very reactive $\alpha, \beta$-unsaturated system (154) could be formed more expediently after oxidation by NAD. Furthermore, if adenine is additionally eliminated, a highly reactive 2,4-cyclopentadien-1-one (155) could be generated. 


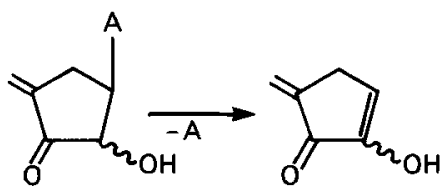

156

157

The oxidized form of neplanocin (154) could potentially inactivate the enzyme through covalent bond formation, or even react with Hcy to produce a regioisomer of the NucHcy metabolite unable to be reduced back by NADH. On the other hand, if the most important metabolite of neplanocin is the NucMet analogue (158), ${ }^{139,141}$ it could also lead to interesting reactions with the methylase due to its reactive double bond. For example, the NucMet metabolite of neplanocin could behave as an inefficient methyl donor which perhaps has the capability of ejecting methionine more readily than the methyl group to give the resonance-stabilized carbocation 159. The exact mechanisms responsible for the interesting effects observed with neplanocin are still the subject of investigation.

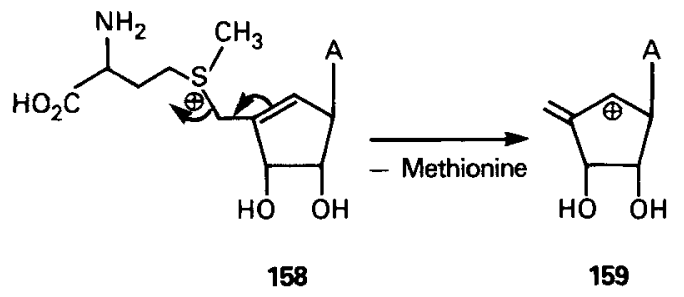

\section{CONCLUSIONS}

The isoteric replacement of the furanose oxygen by a methylene group in nucleosides brings about a substantial change in the biological properties of these compounds. Among the carbocyclic isosteres of the naturally occurring nucleosides, only the pyrimidine carbocyclics C-Thy and C-Cyt possessed in vivo antitumor properties. In the purine series, C-Ado and C-Gua were both inactive as antitumor agents in vivo although C-Ado was highly cytotoxic to L1210 cells in vitro. The systematic replacement by the carbocyclic moiety within the ribo, deoxyribo, ara, and xylo series of selected antitumor nucleoside antimetabolites, led in general to a decrease in antitumor activity except in the case of 8-aza-C-xylo-A. On the contrary, good antiviral activity appeared to be the rule rather than the exception among carbocyclic nucleosides. Highlighting the antiviral usefulness of carbocyclic nucleosides are C-Ara-A and 3-deaza-C-Ado among the purines and 5-I-C-dUrd among the pyrimidines.

Carbocyclic analogues whose structure departed significantly from that of a sugar moiety (i.e., plain cyclopentyl groups lacking the 4'-hydroxymethyl substituent) were generally ineffective with the only exception of the puromycin analogue 125a. Similarly, carbocyclic isosteres of active antitumor carbon nucleosides, such as showdomycin and pyrazofurin, proved to be inactive. Perhaps when the imagination of the medicinal chemist was drawing near to the end in terms of variations and permutation of substituents to be 
performed on the carbocyclic moiety, nature sparked the series into a new domain with the structure of neplanocin. In comparison with the twenty yearold field of conventional carbocyclic nucleosides, the cyclopentenyl, or neplanocin series, is in its infancy. Irrespective of whether or not any of the neplanocin analogues reaches clinical status, the initial results with the few cyclopentenyl purines and pyrimidines examined thus far promises to provide the experimentalist with new powerful and sophisticated tools to probe into important biological mechanisms such as enzymatic methylation and cell differentiation.

The authors wish to thank the help and encouragment received from Dr. John S. Driscoll, Head of the Medicinal Chemistry Section, LPET, and also would like to acknowledge the help of Mrs. Beth Singer for her typing skills.

\section{REFERENCES}

1. J. Goodchild, Topics Antibiot. Chem., 6, 99 (1982).

2. J. G. Buchanan and R. H. Wightman, Topics Antibiot. Chem., 6, 229 (1982).

3. J. A. Montgomery, Med. Res. Rev., 2, 271 (1982).

4. T. Kusaka, H. Yamamoto, M. Shibata, M. Muroi, T. Kishi, and K. Mizuno, J. Antibiot., 21, 255 (1968).

5. T. Kishi, M. Muroi, T. Kusaka, M. Nishikawa, K. Kamiya, and K. Mizuno, Chem. Commun. 852 (1967).

6. T. Kishi, M. Muroi, T. Kusaka, M. Nishikawa, K. Kamiya, and K. Mizuno, Chem. Pharm. Bull., 20, 940 (1972).

7. K. C. Murdock and R. B. Angier, J. Org. Chem., 27, 3317 (1962).

8. K. C. Murdock and R. B. Angier, J. Am. Chem. Soc., 84, 3758 (1962).

9. Y. F. Shealy and J. D. Clayton, J. Am. Chem. Soc., 88, 3885 (1966).

10. Y. F. Shealy and J. D. Clayton, J. Am. Chem. Soc., 91, 3075 (1969).

11. H. J. Schaeffer and R. D. Weimar, Jr., J. Org. Chem., 25, 774 (1960).

12. H. F. Schaeffer, D. D. Godse and G. Liu, I. Pharm. Sci., 53, 1510 (1964).

13. Y. F. Shealy and C. A. O'Dell, J. Het. Chem., 13, 1041 (1976).

14. Y. F. Shealy, C. A. O'Dell, and M. C. Thorpe, J. Het. Chem., 18, 383, (1981).

15. Y. F. Shealy, C. A. O'Dell, M. C. Thorpe, and W. C. Coburn, Jr., J. Het. Chem., 20, 655 (1983).

16. M. Arita, K. Adachi, Y. Ito, H. Sawai, and M. Ohno, Nucleic Acids Symp. Ser., 11, 13 (1982).

17. M. Arita, K. Adachi, Y. Ito, H. Sawai, and M. Ohno, J. Am. Chem. Soc., 105, 4949 (1983).

18. M.-I. Lim and V. E. Marquez, Tetrahedron Lett., 24, 5559 (1983).

19. M. Jung, G. Offenbacher, and J. Retey, Helv. Chim. Acta, 676, 1915 (1983).

20. A. Holy, Nucleic Acids Res., Spec. Publ, 1, s73 (1975).

21. A. Holy, Collect. Czech. Chem. Commun., 41647 (1976).

22. A. K. Saksena, Tetrahedron Lett., 21, 133 (1980).

23. R. C. Cermak and R. Vince, Tetrahedron Lett., 22, 2331 (1981).

24. B. L. Kam and N. J. Oppenheimer, J. Org. Chem., 46, 3268 (1981).

25. F. Y. Shealy, M. C. Thorpe, W. C. Coburn, Jr., and J. D. Clayton, Chem. Pharm. Bull., 28, 3114 (1980).

26. J. C. Jagt and A. M. van Leusen, J. Org. Chem., 39, 564 (1974).

27. S. Daluge and R. Vince, Tetrahedron Lett., 3005 (1976).

28. R. Vince and S. Daluge, J. Med. Chem., 20, 612 (1977).

29. S. Daluge and R. Vince, J. Org. Chem, 43, 2311 (1978).

30. R. Vince and S. Daluge, J. Org. Chem., 45, 531 (1980).

31. M. Ohno, Y. Ito, M. Arita, T. Shibata, K. Adachi, and H. Sawai, Tetrahedron, 40, 145 (1984).

32. S. Danishefsky, M. Hirana, K. Gombatz, T. Harayama, E. Berman, and P. F. Schuda, I. Am. Chem. Soc., 101, 7020 (1979).

33. J. H. Lister in Fused Pyrimidines, Part II, D. J. Brown, Ed., Wiley, 1971, p. 31.

34. D. J. Brown, Ed., The Pyrimidines, Wiley, 1962, p. 87. 
35. G. Shaw and R. W. Warrener, I. Chem. Soc., 153 (1958).

36. G. Shaw and R. W. Warrener, J. Chem. Soc., 157 (1958).

37. F. Y. Shealy and J. D. Clayton, J. Pharm. Sci., 62, 1252 (1973).

38. R. Marumoto, Y. Yoshioka, Y. Furukawa, and M. Horyo, Chem. Pharm. Bull., 24, 2624 (1976).

39. Y. F. Shealy, J. D. Clayton, G. Arnett, and W. M. Shannon, J. Med. Chem,, 27, 670 (1984).

40. Y. F. Shealy and J. D. Clayton, I. Pharm. Sci., 62, 1432 (1973).

41. Y. F. Shealy and C. A. O'Dell, Tetrahedron Lett. 2231 (1969).

42. Y. F. Shealy, C. A. O'Dell, W. M. Shannon, and G. Arnett, J. Med. Chem., 27, 1416 (1984).

43. R. Vince, U.S. Patent 4,383,114, May 10, 1983. Chem. Abstr., 99, 38790q (1983).

44. H. Lee and R. Vince, J. Pharm. Sci., 69, 1019 (1980).

45. R. Vince, J. Brownell, and S. Daluge, J. Med. Chem., 27, 1358 (1984).

46. Y. F. Shealy and J. D. Clayton, J. Pharm. Sci., 62, 858 (1973).

47. Y. F. Shealy, J. D. Clayton, and C. A. O'Dell, J. Het. Chem., 10, 601 (1973).

48. J. A. Montgomery, S. J. Clayton, H. J. Thomas, W. M. Shannon, G. Arnett, A. J. Bodner, I. K. Kion, G. L. Cantoni, and P. K. Chiang, J. Med. Chem., 25, 626 (1982).

49. J. A. Secrist, III, S. J. Clayton, and J. A. Montgomery, J. Med. Chem., 27, 534 (1984).

50. M. Legraverend, J. M. Lhoste, J. M. Bechet, and E. Bisagni, Eur. J. Med. Chem., 18, 269 (1983).

51. M. Legraverend, J. M. Lhoste, and E. Bisagni, Tetrahedron, 40, 709 (1984).

52. J. A. Montgomery and K. Henson, J. Med. Chem., 10, 665 (1967).

53. H. Ohno, T. Itoh, A. Nomura, and Y. Mizuno, Nucleosides \& Nucleotides, 3, 345 (1984).

54. L. L. Bennett, Jr., P. W. Allan, and D. L. Hill, Mol. Pharmacol., 4, 208 (1968).

54a. M. Suno, K. Tsukamoto and Y. Sugino, Cell Struct. Funct., 5, 115 (1980).

55. K. Imai, S. Fujii, K. Takanohasi, Y. Rurukawa, T. Masuda, and M. Horijo, J. Org. Chem., 34, 1547 (1969).

55a. M. Ikehara and T. Fukui, J. Biochem., 73, 945 (1973).

56. D. L. Hill, S. Straight, P. W. Allan, and L. L. Bennett, Jr., Mol. Pharmacol., 7, 375 (1971).

57. L. L. Bennett, Jr., R. W. Brockman, S. C. Shaddix, J. D. Clayton, and Y. F. Shealy, Proc. Am. Assoc. Cancer Res., 1366 (1984).

58. P. W. Allan, L. L. Bennett, Jr., and B. J. Bowdon, Proc. Am. Assoc. Cancer Res., 1362 (1984).

59. L. L. Bennett, Jr., M. H. Vail, P. W. Allan, and S. C. Shaddix, Biochem. Pharmacol., 22, 1221 (1973).

60. D. L. Hill, S. Straight, and P. W. Allan, I. Protozool, 17, 619 (1970).

60a. T. Kusaka, J. Antibiot., 24, 756 (1971).

61. L. L. Bennett, Jr., W. M. Shannon, P. W. Allan, and G. Arnett, Ann. N.Y. Acad. Sci., 255, 342 (1975).

61a. M. Irie, J. Biochem., 69, 965 (1971).

61b. VR (virus rating) is a measure of antiviral activity which takes into account the degree of inhibition of virus-specific cytopathogenic effects and the degree of cytotoxicity produced by the test compound. A VR $>1.0$ indicates definite antiviral activity, a VR of $0.5-0.9$ indicates marginal antiviral activity, and a VR $<0.5$ indicates no significant activity.

62. C. A. O'Dell and Y. F. Shealy, Nucleic Acid Chem., 1, 161 (1978).

63. R. Vince, S. Daluge, H. Lee, W. M. Shannon, G. Arnett, T. W. Schafer, T. L. Nagabhushan, P. Reichert, H. Tsai, Science, 221, 1405 (1983).

64. A. Holy, Collect. Czech. Chem. Commun., 41, 2096 (1976).

65. Y. F. Shealy and C. A. O'Dell, J. Het. Chem., 13, 1015 (1976).

66. Y. F. Shealy, C. A. O'Dell, W. M. Shannon, and G. Arnett, J. Med. Chem., 26, 156 (1983).

67. Y. F. Shealy, J. L. Frye, N. F. DuBois, S. C. Shaddix, and R. W. Brockman, J. Med. Chem., 24, 1083 (1981).

68. W. M. Shannon, G. Arnett, L. Westbrook, Y. F. Shealy, C. A. O'Dell, and R. W. Brockmann, Antimicrob. Ag. Chemother, 20, 769 (1981).

69. Y. F. Shealy and C. A. O'Dell, J. Het. Chem., 13, 1353 (1976).

70. Y. F. Shealy and C. A. O'Dell, I. Het. Chem., 17, 353 (1980).

71. Y. F. Shealy and C. A. O'Dell, J. Pharm. Sci, 68, 668 (1979).

72. R. W. Brockman, J. W. Carpenter, C. A. O'Dell, Y. F. Shealy, and L. L. Bennett, Jr., Fed. Proc., 37, 234 (1978).

73. S. Yazinuma, N. Muto, M. Tsujino, Y. Sudate, M. Hayashi, and M. Otani, J. Antibiot., 34, 359 (1981). 
74. S. Yaginuma, M. Tsujino, N. Muto, M. Otani, M. Hayashi, F. Ishimura, T. Fujii, S. Watanabe, T. Matsuda, T. Watanabe, and J. Abe, Curr. Chemother. Infect. Dis., Proc. Int. Congr., 2, $1558(1980)$

75. M. Tsujino, S. Yaginuma, T. Fujii, K. Hayano, T. Matouda, T. Watanabe, and J. Abe, Curr. Chemother. Infect. Dis., Proc. Int. Congr., 2, 1559 (1980).

76. M. Hayashi, S. Yaginuma, H. Yoshioka, and N. Nakatsu, J. Antibiot., 34, 675 (1981).

76a. M. Hayashi, S. Yaginuma, N. Muto, and M. Tsujino, Nucleic Acids Symp. Ser., 8, s65 (1980).

76b. M. Yamazaki, K. Hamada, Y. Yamagata, T. Fujiwara, K. Tomita, K. Fukukawa, T. Ueda, and T. Hirano, Acta Crystallogr., B38, 1176 (1982).

77. M. Arita, K. Adachi, H. Sawai, and M. Ohno, Nucleic Acid Res. Symp. Ser., 12, 25 (1983).

78. M.-I. Lim and V. E. Marquez, Tetrahedron Lett., 24, 4051 (1983).

79. K. Fukukawa, T. Ueda, and T. Hirano, Chem. Pharm. Bull., 29, 597 (1981).

80. K. Fukukawa, T. Ueda, and T. Hirano, Chem. Pharm. Bull., 31, 1582 (1983).

80a. K. Fukukawa, T. Ueda, and T. Hirano, Chem. Pharm. Bull., 31, 1842 (1983).

81. K. Kinoshita, M. Gayashi, T. Hirano, K. Natatsu, K. Fukukawa and T. Ueda, Nucleosides \& Nucleotides, 2, 319 (1983).

82. Japanese Patent JP 57,102,889. June 26, 1982. Chem. Abstr., 98, 4750r (1983).

83. S. Yaginuma and T. Fujii, German Patent DE 3,148, 363. Sept. 16, 1982. Chem. Abstr., 99, 5975a (1984).

84. Japanese Patent JP 58, 183, 691. Oct. 26, 1983. Chem. Abstr., 100, 103821f (1984).

85. Drug Evaluation Branch, Developmental Therapeutics Program, DCT, NCI, Bethesda, MD, NSC No, 316458.

86. M.-I. Lim, J. D. Moyer, R. L. Cysyk, and V. E. Marquez, J. Med. Chem., 27, 1536 (1984)

87. J. D. Moyer, personal communication.

88. R. I. Glazer, M. C. Knode, M.-I. Lim, and V. E. Marquez, Biochem. Pharmacol in press.

89. R. I. Glazer, personal communication.

90. R. I. Glazer, personal communication.

91. R. J. Suhadolnick, Nucleosides as Biological Probes, Wiley, 1979.

92. G. D. Daves, Jr., and C. C. Cheng, Prog. Med. Chem., 13, 304 (1976).

93. S. Hanessian and A. G. Pernet, Adr. Carbohydr. Biochem. 33, 111 (1977).

94. S. R. James, J. Carboydr. Nucleos. Nucleot., 6, 417 (1979).

95. J. G. Buchanan, Prog. Chem. Org. Natl. Prod., 44, 16 (1983).

96. J. D. Fissekis and B. A. Market, J. Org. Chem., 31, 2945 (1966).

97. J. D. Fissekis and B. M. Creegan, J. Org. Chem., 32, 3595 (1967),

98. A. J. Playtis and J. D. Fissekis, J. Org. Chem., 40, 2488 (1975).

99. G. Just and S. Kim, Tetrahedron Lett., 1063 (1976).

100. G. Just and S. Kim, Can. J. Chem., 55, 427 (1977).

101. G. Just and S. Kim, Can. J. Chem., 54, 2935 (1976).

102. G. Just and B. Chalard-Faure, Can. J. Chem., 54, 861 (1976).

103. G. Just and G. Reader, Tetrahedron Lett., 1525 (1973).

104. G. Just and G. Reader, Tetrahedron Lett., 1521 (1973).

105. G. Just, G. Reader, and B. Chalard-Faure, Can. I. Chem., 54, 849 (1976).

106. A. K. Saksena, Tetrahedron Lett., 22, 2067 (1981).

107. S. Daluge and R. Vince, J. Med. Chem., 15, 171 (1972).

108. R. Vince and S. Daluge, J. Med. Chem., 17, 578 (1974).

109. S. Petska, R. Vince, S. Daluge, and R. Harris, Antimicrob. Ag. Chemother., 4, 37 (1973).

110. R. Vince, S. Daluge and M. Palm, Biochem. Biophys. Res. Commun., 46, 866 (1977).

111. P. H. Duquette, C. L. Ritter, and R. Vince, Biochemistry, 13, 4855 (1974).

112. T. Suami, K. Tadano, M. Ayabe, and Y. Eomori, Bull. Chem. Soc. Jap., 51, 855 (1978).

113. T. Suami, S. Nishiyama, K. Tadano, and F. W. Lichtenthaler, Bull. Chem. Soc. Jap., 46, 2562 (1973).

114. K. Tadano, Y. Emori, M. Ayabe, and T. Suami, Bull. Chem. Soc. Jap., 50, 1572 (1977).

115. K. Tadano, S. Horiuchi, and T. Suami, Bull. Chem. Soc. Jap., 51, 897 (1978).

116. T. Suami, Y. Fukai, Y. Sakota, M. Karimoto, N. Takoi, and Y. Tsukamoto, Bull. Chem. Soc. Jap., 44, 1695 (1971).

117. T. Suami, Y. Sato, Y. Fukai, and Y. Sakota, J. Het. Chem, 6, 663 (1969).

118. R. T. Borchardt, J. Med. Chem., 23, 347 (1980).

118a. G. A. Maw, in The Chemistry of the Sulphonium Group, part 2, C. M. J. Stirling Ed., John Wiley, 1981, p. 703. 
119. R. T. Borchardt, The Biochemistry of Adenosylmethionine, F. Salvatore, E. Burek, V. Zappia, H. G. Williams-Ashman, and F. Schlenk, Eds., Columbia Univ. Press, 1979, p. 151.

120. G. L. Cantoni, P. K. Chiang, in Natural Sulfur Compounds: Novel Biochemical and Structural Aspects, D. Cavallini, G. E. Gaull, V. Zappia, Eds. Plenum Press, 1980, p. 67.

121. P. M. Veland, Pharm. Rev., 34, 223 (1982).

122. R. D. Walker and J. A. Duerre, Can. J. Biochem., 53, 312 (1975).

123. P. K. Chiang, H. H. Richards, and G. L. Cantoni, Mol. Pharmacol., 13, 939 (1977).

124. P. K. Chiang and G. L. Cantoni, Biochem. Pharmacol., 28, 1897 (1979).

125. J. P. Bader, N. R. Brown, P. K. Chiang, and G. L. Cantoni, Virology, 89, 494 (1978).

126. S. Muthukrishnan, B. Moss, J. A. Cooper, and E. S. Maxwell, I. Biol. Chem., 253, 1710 (1978).

127. E. DeClercq and J. A. Montgomery, Antiviral Res., 3, 17 (1983).

128. A. Pierre, M. Richou, F. Lawrence, M. Robert-Gero, and P. Vigier, Biochem. Biophys. Res. Commun., 76, 813 (1977).

129. F. Nau, Biochemie (Paris) 58, 629 (1976).

129a. E. Randerath, A. S. Gopalakrishnan, R. C. Gupta, H. P. Agrawal, and K. Randerath, Cancer Res., 41, 2863 (1981).

130. P. K. Chiang, Y. S. Im, and G. L. Cantoni, Biochem. Biophys. Res. Commun., 94, 174 (1980).

131. J. L. Palmer and R. H. Abeles, J. Biol. Chem., 251, 5817 (1976).

132. J. L. Palmer and R. H. Abeles, J. Biol. Chem., 254, 1217 (1979).

133. T. P. Zimmerman, R. D. Deeprose, G. Wolberg, and G. S. Duncan, Biochem. Biophys. Res. Commun., 91, 977 (1979).

134. T. P. Zimmerman, G. Wolberg, G. S. Duncan, and G. B. Elion, Biochemistry, 19, 2252 (1980).

134a. J.-S. Schanche, T. Schanche, P. M. Ueland, and J. A. Montgomery, Cancer Res., 44, 4297 (1984).

135. A. Guranowski, J. A. Montgomery, G. L. Cantoni, and P. K. Chiang, Biochemistry, 20, 110 (1981).

135a. J. K. Coward and E. P. Slisz, I. Med. Chem., 16, 460 (1973).

135b. R. T. Borchardt and Y.-S. Wu, J. Med. Chem., 19, 197 (1976).

135c. J. K. Coward and W. D. Sweet, J. Med. Chem., 15, 381 (1972).

136. T. Ishikura, H. Nakamura, T. Sugawara, T. Itoh, A. Nomura, and Y. Mizuno, Nucleic Acids Symp. Ser., 12, 119 (1983).

137. R. H. Abeles, S. Fish and B. Lapinkas, Biochemistry, 21, 5557 (1982).

138. R. T. Borchardt, B. T. Keller, U. Pathel-Thombre, J. Biol. Chem., 259, 4353 (1984).

139. R. I. Glazer and M. C. Knode, J. Biol. Chem., 259, 12964 (1984).

140. P. P. Saunders, Proc. Am. Assoc. Cancer Res., 89 (1984).

141. B. T. Keller and R. T. Borchardt, Biochem. Biophys. Res. Commun., 120, 131 (1980).

141a. R. K. Gordon, N. D. Brown, and P. K. Chiang, Biochem. Biophys. Res. Commun., 114, 505 (1983).

142. J. Stubbe and J. W. Kozarich, J. Am. Chem. Soc., 102, 2505 (1980).

143. J. Stubbe and J. W. Kozarich, J. Biol. Chem., 255, 5511 (1980).

144. R. H. Abeles, Chem. Eng. News, Sept. 19, 1983, p. 48. 